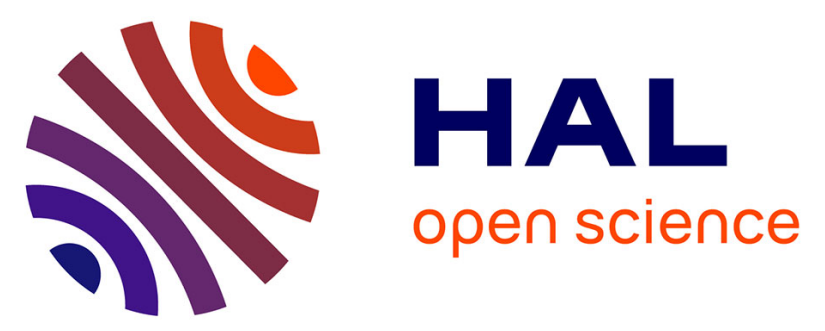

\title{
Quantifying Sediment Transport Dynamics on Alluvial Fans From Spatial and Temporal Changes in Grain Size, Death Valley, California
}

Sam Brooke, Alexander Whittaker, John Armitage, Mitch d'Arcy, Stephen Watkins

\section{To cite this version:}

Sam Brooke, Alexander Whittaker, John Armitage, Mitch d'Arcy, Stephen Watkins. Quantifying Sediment Transport Dynamics on Alluvial Fans From Spatial and Temporal Changes in Grain Size, Death Valley, California. Journal of Geophysical Research: Earth Surface, 2018, 123 (8), pp.2039-2067. 10.1029/2018JF004622 . insu-02919845

\section{HAL Id: insu-02919845 https://hal-insu.archives-ouvertes.fr/insu-02919845}

Submitted on 10 Nov 2020

HAL is a multi-disciplinary open access archive for the deposit and dissemination of scientific research documents, whether they are published or not. The documents may come from teaching and research institutions in France or abroad, or from public or private research centers.
L'archive ouverte pluridisciplinaire HAL, est destinée au dépôt et à la diffusion de documents scientifiques de niveau recherche, publiés ou non, émanant des établissements d'enseignement et de recherche français ou étrangers, des laboratoires publics ou privés. 


\section{Journal of Geophysical Research: Earth Surface}

\section{RESEARCH ARTICLE \\ 10.1029/2018JF004622 \\ Key Points: \\ Quantifying Sediment Transport Dynamics on Alluvial Fans From Spatial and Temporal Changes in Grain Size, Death Valley, California}

- Grain size distributions show finer material deposited during the Holocene versus late Pleistocene

- Alluvial fan surface mean and standard deviation are self-similar through time

- Modeled relative mobility of grain sizes shows coarser material more mobile during the late Pleistocene

Supporting Information:

- Supporting Information S1

Correspondence to:

S. A. S. Brooke,

s.brooke14@imperial.ac.uk

Citation:

Brooke, S. A. S., Whittaker, A. C., Armitage, J. J., D'Arcy, M., \& Watkins, S. E. (2018). Quantifying sediment transport dynamics on alluvial fans from spatial and temporal changes in grain size, Death Valley, California. Journal of Geophysical Research: Earth Surface, 123, 2039-2067. https://doi.org/10.1029/2018JF004622

Received 22 JAN 2018

Accepted 22 JUN 2018

Accepted article online 18 JUL 2018

Published online 31 AUG 2018

(2)2018. American Geophysical Union. All Rights Reserved.

\author{
Sam A. S. Brooke ${ }^{1}$ D, Alexander C. Whittaker ${ }^{1}$, John J. Armitage ${ }^{2}$ iD, Mitch D’Arcy ${ }^{3}$, \\ and Stephen E. Watkins ${ }^{1}$ \\ ${ }^{1}$ Department of Earth Science and Engineering, Imperial College London, London, UK, ${ }^{2}$ Institut de Physque du Globe de \\ Paris, Dynamique des Fluides Geologiques, Paris, France, ${ }^{3}$ Institute of Earth and Environmental Science, University of \\ Potsdam, Potsdam, Germany
}

\begin{abstract}
How information about sediment transport processes is transmitted to the sedimentary record remains a complex problem for the interpretation of fluvial stratigraphy. Alluvial fan deposits represent the condensed archive of sediment transport, which is at least partly controlled by tectonics and climate. For three coupled catchment-fan systems in northern Death Valley, California, we measure grain size across 12 well-preserved Holocene and late-Pleistocene surfaces, mapped in detail from field observations and remote sensing. Our results show that fan surfaces correlated to the late Pleistocene are, on average, 30-50\% coarser than active or Holocene fan surfaces. We adopt a self-similar form of grain size distribution based on the observed stability of the ratio between mean grain size and standard deviation downstream. Using statistical analysis, we show that fan surface grain size distributions are self-similar. We derive a relative mobility function using our self-similar grain size distributions, which describes the relative probability of a given grain size being transported. We show that the largest mobile grain sizes are between 20 and $35 \mathrm{~mm}$, a value that varies over time and is clearly lower in the Holocene than in the Pleistocene; a change we suggest is due to a drier climate in the Holocene. These results support recent findings that alluvial fan sedimentology can record past environmental change and that these landscapes are potentially sensitive to climatic change over a glacial-interglacial cycle. We demonstrate that the self-similarity methodology offers a means to explore changes in relative mobility of grain sizes from preserved fluvial deposits.
\end{abstract}

Plain Language Summary A key challenge in Earth Science is understanding how landscapes respond to climate. It may be possible to observe measurable differences in certain landscapes settings such as alluvial fans in desert regions. Alluvial fans are believed to be effective recorders of climate, representing a cumulative store of material transported downstream by rainfall-sensitive river systems. In northern Death Valley, California, we measure at high resolution grain size on three alluvial fans with surfaces that date from the Holocene and the arid climate of today to the $20-40 \%$ wetter late-Pleistocene epoch. We find that older late-Pleistocene surfaces are coarser on average than surfaces deposited during the modern and Holocene dry period, suggesting a changing sediment transport regime potentially in response to precipitation. We also show that measured grain size distributions within and between surfaces can be successfully normalized based on the decay in mean grain size and variance downstream, exhibiting a self-similar pattern. Finally, we employ a grain size relative mobility model using our field data to establish which grain sizes are likely to be in transport or locked in the substrate. This model predicts that during the wetter late-Pleistocene mobile grain sizes are up to $40 \%$ larger than during the Holocene.

\section{Introduction}

\subsection{Study Rationale}

Alluvial fans are distinctive landforms commonly found on mountain fronts where a feeder channel flows into an underfilled basin, depositing its supply of sediment to produce a characteristic radial pattern over time (Blair \& McPherson, 1994; Bull, 1964; Denny, 1967; Hooke, 1968; Nichols \& Fisher, 2007). Alluvial fans are net depositional landforms and represent the cumulative sediment flux from an eroding source area as a function of many factors, including channel and hillslope processes (DiBiase \& Whipple, 2011; Forzoni et al., 2014; 
Malmon et al., 2003) and the sediment transport regime on fan surfaces (Clarke et al., 2010; Harvey, 2012; Kim \& Jerolmack, 2008; Kim \& Paola, 2007; Mohrig et al., 2000; Reitz \& Jerolmack, 2012). The size and shape of alluvial fans is controlled by the rate and volume of sediment delivered from the catchment and the accommodation of the basin (Allen \& Hovius, 1998; Whipple \& Trayler, 1996); factors that are modulated by tectonic and climatic boundary conditions (Harvey, 2002, 2005; Quigley et al., 2007; Ritter et al., 1995; Schlunegger \& Norton, 2015; Suresh et al., 2007).

It has been suggested that alluvial fan stratigraphy may contain signals of environmental forcing, expressed via sediment fluxes, (e.g., Allen \& Densmore, 2000; Densmore et al., 2007), the caliber of this exported sediment (Schlunegger \& Norton, 2013, 2015), and the rate at which it fines downstream (e.g., D'Arcy et al., 2016; Whittaker et al., 2011). Specifically, an increase in volumetric sediment flux may reflect a transient response to changes in tectonic perturbation, either in terms of fault throw (Armitage et al., 2011; Whittaker et al., 2010) or regional uplift (Garefalakis \& Schlunegger, 2018; Schlunegger \& Norton, 2013), climatic changes such as an increase in mean rainfall (Foreman, 2014; Schmitz \& Pujalte, 2007; Syvitski \& Milliman, 2007), storminess (Miller et al., 2010), or deglaciation (Savi et al., 2014). Trends in sediment caliber in transport-limited fluvial systems can reflect changes in dominant hydraulic conditions, wherein larger grain sizes can be attributed to higher flow velocities or discharges that are a consequence of increased rainfall amount or intensity (Schlunegger \& Norton, 2015) or increasing slope (Garefalakis \& Schlunegger, 2018). In supply-limited systems, grain size changes can result from an increased availability of coarse sediment, potentially in response to an erosional pulse induced by tectonic uplift (e.g., Whittaker et al., 2010, 2011) or changes in weathering processes that generate sediment from bedrock, for example, across a climate gradient (Blum \& Törnqvist, 2000; Leeder et al., 1998; Riebe et al., 2015; Sklar et al., 2017). Finally, the spatial trends in grain size have been used to better understand the relationships between sediment supply and the filling of accommodation, where a change in down system fining rate may indicate a change in subsidence rate down system (Duller et al., 2010; Paola et al., 1992; Robinson \& Slingerland, 1998). In this paper we investigate grain size distributions on alluvial fans as a means to quantify changes in sediment transport over time.

The relationship between sediment flux and grain size can be viewed as a mass balance problem, in which the downstream stratigraphic expression of sediment supply involves grain size fractionation downstream as a function of available accommodation space and the input grain size distribution (Allen et al., 2013, 2017; Armitage et al., 2011, 2013; Duller et al., 2010; Fedele \& Paola, 2007; Paola \& Martin, 2012; Strong et al., 2009). From this, it has been possible to reconstruct the sediment budgets, tectonic subsidence, and erosion rates in structurally controlled terrestrial basins in the Spanish Pyrenees from grain size fining rates where the spatial distribution of sediment deposition is known (Michael et al., 2013, 2014; Whittaker et al., 2011). Using a similar methodology, recent work by D'Arcy et al. (2016) has illustrated how time-integrated grain size fining patterns on late Pleistocene and Holocene alluvial fan surfaces in Death Valley can record sediment flux changes through time. This study linked a $20 \%$ decrease in sediment flux with the corollary $30 \%$ drop in precipitation between $70 \mathrm{ka}$ and the present day in this region.

However, the extent to which different magnitudes and styles of environmental signals are commonly preserved in stratigraphy is a nontrivial question. Complexities, such as whether thresholds for landscape response potentially favor high-magnitude, low-frequency events (Armitage et al., 2011; Simpson \& Castelltort, 2012) and the difficulties of stratigraphic incompleteness (Kemp, 2012; Sadler, 1981; Sadler \& Strauss, 1990) have all been raised. Other authors have considered the spatial and temporal changes in geomorphic processes, such as channel avulsions and questioned how they translate to stratigraphy (Ganti et al., 2014). Stratigraphic insensitivity to certain climate events (e.g., Sambrook Smith et al., 2010) and/or the potential for buffering or modification of climatic signals during sediment transport (e.g., Jerolmack \& Paola, 2010) have all received considerable attention.

In principle, catchment-fan systems provide a way of addressing some of these issues, offering an integrated record of sediment flux through time, with constrainable dimensions and often near-total preservation of exported material (e.g., Allen, 2008; Allen \& Hovius, 1998; Densmore et al., 2007). Numerical and physical experiments both indicate the potential sensitivity of catchment-fan systems to record changes in sediment supply through time (Allen \& Densmore, 2000; Allen \& Hovius, 1998; Armitage et al., 2011, 2013; Densmore et al., 2007, Rohais et al., 2012). Simplified basin-fill numerical models have shown that an increase in erosion due to higher precipitation rates under steady tectonic forcing will produce a predictable increase in sediment supply, forming an onlapping layer of coarse material that progrades into the basin 
(Armitage et al., 2011, 2013; Paola, 2000). This effect should be apparent in well-coupled catchment-fan systems where the effect of buffering is limited (Armitage et al., 2013; Clevis et al., 2003; Forzoni et al., 2014). However, it has been shown in flume tank experiments that alluvial fans can exhibit complex autogenic behavior, even under steady forcing, due to feedbacks between sediment supply and fan gradient (Nicholas et al., 2009; Kim \& Jerolmack, 2008; Reitz \& Jerolmack, 2012). This intrinsic noise in alluvial fan deposition may set a lower limit, or filter, on which climate perturbations may be recorded by the stratigraphic record (Jerolmack \& Sadler, 2007).

\subsection{Grain Size Distributions and Sediment Mobility}

Many sediment transport models are based on the assumption that coarser material is progressively lost downstream due to the preferential transportation or storage of different grain sizes due to hydraulic sorting under varying shear stress conditions (Parker, 1991a, 1991b; Parker \& Toro-Escobar, 2002; Toro-Escobar et al., 1996). Stratigraphy and/or older inactive sediments must (in some form) represent a time-integrated product of a given sediment transport regime that has controlled the mobility of given grain sizes and thus what caliber of sediment may be preferentially moved or locked into long-term storage. Fedele and Paola (2007) define a relative mobility function, $J$, which describes the ratio between the fraction of material, for a given grain size, that is in transport, $p$, and the fraction which is locked in the substrate, $f$, that is,

$$
J=p / f
$$

Fedele and Paola (2007) propose that gravel grain size distributions are self-similar when transformed using the mean and standard deviation of the sample distribution. This transformation of given gravel size, $D$, can be applied to produce a complete distribution of self-similar grain size, $\xi$,

$$
\xi=\frac{D-\bar{D}(x *)}{\sigma(x *)}
$$

where the local mean grain size $(\bar{D})$, and local standard deviation $(\sigma)$ at a given spatial coordinate $(x *)$ are known. The caveat for the application of a self-similar grain size transformation is a spatial requirement that states that the downstream decay in mean and standard deviation of hydraulically sorted gravel grain size distributions is approximately the same. Model-independent field observations show that this is a valid assumption in cases such as in Eocene Collegats and Montsor alluvial fan successions in Spanish Pyrenees (Duller et al., 2010; Whittaker et al., 2011), and alluvial fans in northern Death Valley (D'Arcy et al., 2016). However, Miller et al. (2014) show that the mean and standard deviation of grain size distributions in some alluvial fans may not proportionally decay downstream and hence do not conform to the definition of self-similarity. We therefore lack a comprehensive testing of whether the hydraulic sorting of gravels on alluvial fans ordinarily produces self-similar grain size distributions. To solve this we require high-resolution grain size data sets from multiple alluvial fans with active hydraulic processes and preserved terraces.

Given the observation of self-similar gravel fractionation downstream and self-similar grain size distributions, Fedele and Paola (2007) derive a self-similar solution to the relationship between a given substrate grain size composition using the $J$ parameter and distributions of $\xi$ (see Text $S 1$ in the supporting information). These self-similar solutions are based on the outcomes of steady state, numerically tuned fluvial gravel transportation models that predict how bedload gravel fractionates downstream (Parker, 1991a). From these models, Fedele and Paola (2007) show that a nonlinear relationship exists between mobility parameter $J$ and self-similar grain size $\xi$. Importantly, the relationship between $J$ and $\xi$ remains the same for different locations downstream, plotting approximately on the same relative mobility curve in a self-similar manner. From this, Fedele and Paola (2007) developed a framework by which complex hydraulic sorting processes can be collected using the single relative mobility function $J$ dependent on self-similar grain size $\xi$, where it can be probabilistically assumed that $J>1$ corresponds to a grain size that is preferentially transported; $J<1$ a grain size that is preferentially stored in substrate; and $J=1$ for grain sizes that equally likely to be in transport versus storage.

The analytical form of relative mobility, $J$, is approximated as an exponential function of the self-similar grain size variable, $\xi$, and takes the form of equation

$$
J=a_{g} e^{-b_{g} \xi}+c_{g}
$$


where values for constants $a_{g}, b_{g}$, and $c_{g}$ must be assigned or found empirically (D'Arcy et al., 2016; Fedele \& Paola, 2007). The derivation of $J$ depends on two constants, $C_{1}$ and $C_{2}$, which describe the systematic partitioning of the gravel supply variance downstream relative to the mean grain size $\left(C_{2}\right)$ or the standard deviation $\left(C_{1}\right)$ at a location. The $C_{1}$ value effectively describes the rate of gravel supply extraction into the substrate, where higher values represent faster rates of downstream fining (Duller et al., 2010). The values for $C_{1}$ and $C_{2}$ are unlikely to be universal across all fluvial systems but can be found empirically from the coefficient of variation in gravel grain size distributions (Duller et al., 2010; Fedele \& Paola, 2007), where $C_{1}$ is believed to range between 0.55 and 0.9 (Fedele \& Paola, 2007). Full details of the $C_{1}$ and $C_{2}$ constants and the derivation of self-similarity solutions to the relationship between the substrate fraction and the mobility parameter $J$ can be found in the supporting information (Text S1), Fedele and Paola (2007), and Duller et al. (2010).

The self-similar solutions of Fedele and Paola (2007) are an effective tool to collapse grain size fining trends from disparate sediment routing systems, without any presupposition of hydraulic parameters such as channel dimension or slope. Consequently, in observing the self-similarity in preserved grain size distributions, we move closer to identifying and understanding both the dynamics and self-organizing properties of fluvial systems. For example, in the study of gravel-dominated alluvial fan systems, the self-similar model has demonstrated its effectiveness for both active (D'Arcy et al., 2016) and ancient settings (Duller et al., 2010; Whittaker et al., 2011) owing to its nonspecificity toward hydraulic regime (e.g., rivers versus alluvial fans). This is advantageous in a number of scenarios, for example, the stratigraphic interpretation of fluvial-transported gravels where hydraulic constraints are unknown, as well as modeling the grain size product of long-term gravel transportation without a reliance on underdetermined hydraulic parameters. Instead, for the application of the self-similar model we require some form of derivation of time-dependent relative mobility from self-similar grain size data, the agreed parameters of which remain uncertain for different geomorphic settings (Duller et al., 2010).

In this paper, we use field measurements of gravel grain size distributions for alluvial fan surfaces in Death Valley as a means of testing whether they are self-similar and to calculate the relative mobility of specific grain sizes. We focus on gravel distributions as numerical bed load transportation models for gravel are demonstrably self-similar (Fedele \& Paola, 2007; Parker, 1990b, 1990a), alluvial fan sediments are dominated by gravel grade material, and we can measure gravel clast dimensions easily and accurately in the field.

Specifically, we answer three important questions. First, do alluvial fans exhibit statistically significant changes in grain size over time and space? Second, are their deposit grain size distributions statistically self-similar? Third, can we use field grain size measurements to gain new insights into the systematic relative mobility regime for alluvial fans? We address these questions using a high-resolution field grain size data set from three alluvial fans in Death Valley, comprising 12 surfaces and 18,700 individual clast counts. We statistically analyze the collected grain size distributions and tune the self-similarity solutions of Fedele and Paola (2007) to our field data to uncover whether the relative mobility of grain sizes on alluvial fans can represent a valuable record of landscape response to climatic perturbation.

\section{Study Area: Death Valley, United States}

\subsection{Geological Context}

Death Valley (Figure 1a) is an oblique pull-apart basin at the boundary between the strike-slip East California Shear Zone to the west and the extensional Basin and Range Province to the east (Burchfiel \& Stewart, 1966). Death Valley is thought to have been formed by a multiphase extension process, at first driven by the Basin and Range-style low-angle extension between 18 and 5 Ma followed by the initiation at 3 Ma of strike-slip movement in the East California Shear Zone (Norton, 2011), which produced the deep pull-apart depression of Death Valley as we observe it today. Global Positioning System-derived multidecadal estimates of fault movement in the region, corroborated by apatite thermochronology (Ferrill et al., 2012), constrain the east-west extension of Death Valley at approximately $6 \mathrm{~mm} /$ year (Miller et al., 2001). The northern portion of Death Valley, centered on the Mesquite Flat, is dissected by the Northern Death Valley Fault Zone; Figure 1b), a dextral strike-slip fault complex with a slip rate of 4-5 mm/year (Frankel et al., 2007; Machette et al., 2001; Piety, 1996). Normal fault complexes, such as the Grapevine Fault Zone to the north, bounding the southern Grapevine Mountains and the Towne Pass Fault to the northwest of the Panamint Range (Figure 1b) are less active, with vertical slip rates of less than $0.2 \mathrm{~mm} /$ year (Klinger, 2002; Machette et al., 2001; Machette \& Klinger, 2002; Piety, 1996). 

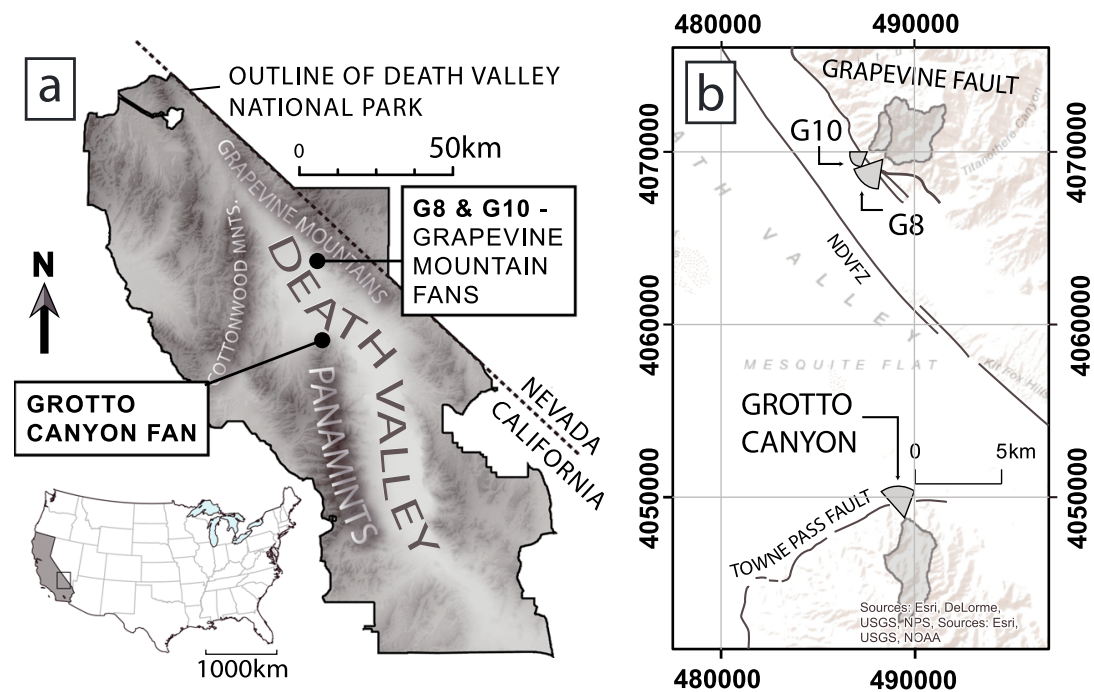

Figure 1. (a) Location of Death Valley National Park, eastern California, with study sites at the foot of the Grapevine and Panamint ranges in the northern portion of Death Valley. (b) Locations of fans studied and their associated catchments (gray, semitransparent polygons), with G8 and G10 on to the north of the Mesquite Flats crossing the normal fault boundaries of the Grapevine Fault Zone and the Grotto Canyon Fan crossing the easternmost mapped trace of the Towne Pass normal fault.

The contemporary climate of Death Valley is arid, with a mean annual precipitation of $57 \mathrm{~mm} / \mathrm{year}$ and mean annual temperature of $25^{\circ} \mathrm{C}$ over the previous century (Western Regional Climate Center, 2017). By comparison, during the late Pleistocene the region was cooler and wetter than present conditions, with a combination of increased runoff and reduced evaporation sustaining pluvial lakes such as Lake Manly in Badwater Basin, an endorheic basin in southern Death Valley (Blackwelder, 1933; Ku et al., 1998; Lowenstein et al., 1999). Climate proxies for the region include hydrological restorations of lake levels from carbon dating (Bacon et al., 2006), U-series dating of lakeshore carbonates (Ibarra et al., 2014; Ku et al., 1998), salt core records (Lowenstein et al., 1999), $\delta^{18}$ O records from the Devil's Hole speleothem (Winograd et al., 1992), and lake cores in Death Valley (Yang et al., 2005). Paleoclimate reconstructions of the Last Glacial Maximum, from the CMIP5 data set collated by Hijmans et al. (2005), show that for the Last Glacial Maximum the temperate was $6^{\circ} \mathrm{C}$ cooler on average in Death Valley, with a mean annual rainfall $20-40 \%$ greater than present Holocene conditions.

\subsection{Alluvial Fans}

The rapid extension of Death Valley has produced accommodation conducive to the growth of large, often coalesced alluvial fans that have been extensively studied and mapped (e.g., Blair, 1999a, 1999b, 1999c, 2000; Bull, 1977; D'Arcy et al., 2016; Denny, 1965; Frankel \& Dolan, 2007; Gillespie et al., 1984; Hooke, 1972; Klinger, 2002) with the age of surfaces established on a multitude of geomorphological and sedimentological criteria. Broadly, older fan surfaces are more elevated toward the fan apices, as subsequent younger surfaces have incised, with older surfaces also exhibiting a greater degree of desert varnishing (Bull, 1991; Hooke, 1972; Hooke \& Dorn, 1992; Hunt \& Mabey, 1966). Stratigraphically, the original work by Hunt and Mabey (1966) divides Quaternary alluvial fans deposits in Death Valley into three groups, Q2, Q3, and Q4, each with a range of subdivisions proposed by subsequent authors (e.g., Bull, 1991; Denny, 1965; Klinger, 2002). The age of these units has been constrained from several studies including cosmogenic-nuclide dating and stratigraphic correlation by Machette et al. (2008) who identify Holocene Q4 units $<12$ ka (Qay), late-Pleistocene Q3 surfaces between 12 and $30 \mathrm{ka}$ (Qayo), and an older Q2 Pleistocene surface between 40 and $100 \mathrm{ka}(\mathrm{Q} / \mathrm{m})$ that coincides with a Q2c surface identified by Frankel et al. (2007).

Within the Holocene, Klinger (2002) also identifies several divisional subsets of Q3; Q3b (4-8 ka) and Q3a (8-12 ka). For older surfaces, Dühnforth et al. (2017) identify and date using ${ }^{10} \mathrm{Be}$ and ${ }^{26} \mathrm{Al}$ cosmogenic nuclides a preserved debris flow surface with a smooth desert pavement on the Warm Spring Fan in southern Death Valley as being between 990 and $630 \mathrm{ka}$ in age. This surface potentially constitutes the characteristics of an early Pleistocene surface (Q1) and highlights how surface relief on a fan decreases over time, in this case within $10^{5}$ years for abandoned debris flow morphology. For more fluvially dominated fans, Frankel and Dolan (2007) show that the decreasing roughness of fan surfaces stabilizes in Death Valley after a period of $70 \mathrm{ka}$ 
as remnants of the original bar and swale morphology diffuse away. Subsequently, surface roughness may increase as incision resumes and new convex hillslope morphology develops, which may be the case for units older than 70 ka in Death Valley (Frankel \& Dolan, 2007).

The fans investigated in this study originate from mountain catchments in two regions of northern Death Valley; two are adjacent alluvial fans that exit the Grapevine mountains (which we call G8 and G10) and one, known as the Grotto Canyon fan, exiting a catchment at the northern tip of the Panamint Range (Figure 1a). The Grapevine fans cross the Grapevine fault and reside approximately $8 \mathrm{~km}$ directly southeast of the entrance to Titus Canyon and $17 \mathrm{~km}$ north of Grotto Canyon (Figure 1b), with catchment bedrock comprising Palaeozoic dolomite of the Bonanza King formation, common to exhumed bedrock in mountain ranges of the region (Workman et al., 2002). The Grotto Canyon fan resides immediately to the east of Mosaic Canyon along the Towne Pass fault (Figure 1b), emanating from a catchment demarcated by ridgelines that rise toward Tucki Mountain $\sim 10 \mathrm{~km}$ to the southwest. Grotto Canyon lithologies range from Bonanza King Formation dolomites to smaller outcrops of late Palaeozoic metasediments (Workman et al., 2002). Today, these fans are predominantly unvegetated due to the extremely arid conditions prevailing in the Holocene. The fans in this study were chosen based on the accessibility of fan surfaces and suitability for making high-density grain size measurements, with 1-2 km lengths enabling traversal of individual fan transects on foot. The Grapevine fans, G8 and G10, were selected as a means to establish similarities between adjacent fans along strike, from the same mountain range and with comparable lithologies. Grotto Canyon was chosen as a comparison of a similar scale fan in the same region of Death Valley but on a separate fault, with differing aspect and source catchment lithology to G10 and G8. The Grapevine fans (G8 and G10) lie 15 km southeast of cosmogenically dated alluvial fans with both Holocene deposits and late-Pleistocene surfaces of circa $70 \mathrm{ka}$ in age (Q2c; Frankel et al., 2007) that can be correlated along strike to aid fan surface mapping. In this study we map each alluvial fan based on the sedimentological and geomorphological characteristics defined by previous authors, aided by fan surface stratigraphic correlation.

\section{Methods and Analysis}

\subsection{Fan Mapping and Remote Sensing}

Prospective alluvial fan measurement sites in this study were identified from remotely sensed imagery of up to $5 \mathrm{~m}$ in resolution (U.S. Department of Agriculture-NAIP 2009) with a corresponding ASTER digital elevation model with a horizontal/vertical resolution of 30/10 m. Detailed alluvial fan maps were produced using a combination of high-resolution field surveys conducted over a 3-week period in October 2015, remotely sensed data and topographic analyses using ground-based telemetry with a TruPulse ${ }^{T M} 200 \mathrm{X}$ laser rangefinder. The rangefinder surveys enabled the height differences between contiguous fan terraces to be measured accurately in the field. The minimum vertical offset between different fan surfaces in this study is $0.5 \mathrm{~m}$.

In the field, a relative chronology of fan surfaces and terraces was produced from observation of terrace elevation, desert varnishing, and the preservation of relict fluvial morphology, where older terraces are increasingly higher than active channels and have gradually lost their original bar and swale morphology. Desert varnish is a common indicator of fan surface age applied in Death Valley (e.g., Denny, 1965; Frankel \& Dolan, 2007; Hooke, 1972), becoming visually noticeable after 2000 years of accumulation and taking approximately 10 ka to heavily coat clasts (Liu \& Broecker, 2000). Using these observables, the broad dissection of fan surfaces between Holocene (Q4, Q3) surfaces and late-Pleistocene surfaces (Q2) is possible by referencing previous published fan unit classifications (e.g., Blair, 1999a; Denny, 1965; Frankel et al., 2007; Frankel \& Dolan, 2007; Hooke, 1972; Klinger, 2002; Owen et al., 2011). Our fan surface chronologies begin with the youngest identifiable units (Q4) that consist of recent flow deposits with weak desert varnish and fresh bar and swale morphology (Denny, 1965). Increasing with age, the older abandoned Holocene surfaces (Q3) are identifiable from a preserved fluvial bar and swale morphology. These Q3 surfaces sometimes form isolated terraces, or islands, within the larger Q4 fan splays that subsequently onlap the Q3 terraces toward the toes of fans (Blair, 1999a; Gillespie et al., 1984; Hunt \& Mabey, 1966). Q3 surfaces generally show a weak to moderate degree of desert varnishing (Denny, 1965; Frankel \& Dolan, 2007; Hunt \& Mabey, 1966). Above the Holocene Q4 and Q3 surfaces are a series of Pleistocene terraces $(\mathrm{Q} 2)$, readily identifiable from a marked difference in terrace heights with moderately to heavily varnished surfaces that progressively show a loss of original fluvial morphology with age (Frankel \& Dolan, 2007). The oldest surfaces are typically the highest elevation fan terraces with the highest degree of varnishing and potential desert pavement development (Hooke, 1972). Denny (1965) describe the Q2 Pleistocene unit as being a weathered gravel, with a smooth surface lacking in any preserved stream flow 
features. Several authors have measured a discernable reduction in surface roughness for surfaces at least 70 ka in age using aerial lidar data (Dühnforth et al., 2017; Frankel \& Dolan, 2007).

Contiguous fan surfaces are most easily identified close to the fan apex, where older Pleistocene fan surface preservation is higher due to greater incisional depths of younger units. In this respect, mapping of fan units begins at the fan apex, where Holocene units were traceable by establishing the location of active depositional channels and lobes on alluvial fan surfaces. The preservation of fan surfaces was also an important consideration in the field, with measurement localities along downstream transects chosen where sediment had not been heavily reworked or mixed with noncontemporaneous sediment from other sources. Beyond reworking by recent flow, the exposure of abandoned surfaces to intermittent rainfall and windblown deposition may subsequently modify surfaces as desert pavement develops over time (McFadden et al., 1987; Pelletier et al., 2007; Wells et al., 1995), producing a subsurface layer of fine material through which clasts can potentially migrate. In the field, the presence of desert pavement constitutes a further postdepositional reworking to evaluate, specifically for the older late-Pleistocene fan deposits. Consideration is made when mapping for postdepositional modification of surface grain size, namely, the presence of interlocking angular grains, a smooth surface, uniformity of grain size over a wide area and a thick layer of fine material below a superficial covering of clasts (section 3.2), each of which is explored in depth in the discussion.

In total, 12 fan surfaces are studied in this paper. Final maps were produced using GIS software in combination with georeferenced field data, with surfaces cross correlated between fans based on field observations and degree of desert varnishing and preserved depositional morphology. Contextual images showing fan surface deposits are shown in the supporting information (Text S2).

\subsection{Grain Size Sampling}

Our data collection approach follows previous applications of the Wolman point count method for fluvially sorted gravels in active river or fan systems and preserved ancient fluvial deposits (e.g., Cowie et al., 2008; D’Arcy et al., 2016; Duller et al., 2010; Garefalakis \& Schlunegger, 2018; Michael et al., 2013; Miller et al., 2014; Whittaker et al., 2010; Wolman, 1954). Measurements were taken in downstream transects at either 100- or 200-m intervals on each surface with grain size being measured along the long axis of the grain. We elected to measure the long (a) axis rather than the intermediate (b) axis because measuring the $b$ axis of grains smaller than $20 \mathrm{~mm}$ in the field can be inaccurate, time-consuming, and difficult to repeat reliably on the same clast. In contrast, the long axis is easy to find and measure accurately, even in repeat surveys. We justify this approach based on our intention to collect a high volume of measurements using a metal rule, where measuring the intermediate axis by hand in the field can be prone to error, or requires slower but more precise tools such as calipers (Bunte et al., 2001; Marcus et al., 1995). The dimensions of fluvially transported clasts also exhibit a systematic ratio between the long and intermediate axes, typically between 0.7 and 0.75 (Blott \& Pye, 2008; Krumbein, 1941), ensuring that the shape of distribution will not differ depending on which axis is measured. Grain size observations taken from gravel bars in active river systems (Litty et al., 2017; Litty \& Schlunegger, 2017) and preserved fanglomerates in stratigraphy (Garefalakis \& Schlunegger, 2018) also show that the ratio between the intermediate axis (b) and the long axis (a) is remarkably stable at $\sim 0.7$. We therefore assume that there is no systematic change in the ratio between the intermediate axis and long axis with clast size, lithology, or location.

Two or four Wolman point counts each of a 100 clasts with a minimum grain size of $1 \mathrm{~mm}$ were taken to capture grain size distributions, with two persons making separate counts of the same sample site to test agreement and mitigate selection bias (Marcus et al., 1995; Wohl et al., 1996). In total, 18,700 individual grains were measured from 12 alluvial fan surfaces at 144 separate locations. Specifically, on G8 we measured 47 sites on four transects of four fan surfaces, on fan G10 we measured 58 sites on five transects on five surfaces and on the Grotto Canyon fan we measured 39 sites on three transects of three fan surfaces.

In patchier areas of fan deposits with characteristic bar and swale morphology it was appropriate to identify two $1-\mathrm{m}^{2}$ quadrats of representative grain size distributions (e.g., coarser versus finer deposits) and produce a combined weighted grain size distribution (after Kondolf, 1997). This approach ensures that gravel grain size measured was representative of the long-term bulk depositional stratigraphy and not of a localized abundance of grain size at the surface, especially in active channels with recent flux that may bypass the system and where surface deposits may have fractionated during transport. To achieve a representative sample, we employed a rigorous sampling strategy that covers entire fan surfaces from apex to toe and included measuring exposed terrace cuts to ensure equivalency to surface measurements. For many predominantly younger 
surfaces we assessed the relative abundance of coarse fraction and fine fraction material due to the prevalence of preserved bar and swale morphology, weighting our results accordingly. For older surfaces the gradual lateral migration of clasts slowly diffuses the original bar and swale texture away and we anticipate that we can capture the spatially averaged grain size distribution from a single grain size count at a given locality. To test whether surface measurements show systematically different gravel grain size distributions from side cuts, we carefully measured surface and side cuts for the same localities on the G8-B surface (see Text S3). In terms of persistence of grain size on exposed surfaces, our coarse-fraction Wolman point count sampling strategy predominantly focuses on grain sizes greater than $5 \mathrm{~mm}$ that are unlikely to be affected by wind or significantly reworked by overland flow. Furthermore, grain sizes larger than $5 \mathrm{~mm}$ are unlikely to be a potential product of weathering processes. Wolman point counts for the gravel fraction of either the surface or subsurface are reproducible to $\pm 5 \mathrm{~mm}$ for the mean, median, and standard deviation of grain size distribution, and within $\pm 10 \mathrm{~mm}$ for the coarse fraction $D_{84}$ (see Text S3).

We derive several statistical metrics for each grain size distribution such as the mean $(\bar{D})$, the standard deviation $(\sigma)$, median grain size $\left(D_{50}\right)$, and the coarse fraction grain size $\left(D_{84}\right)$. We use the coarse fraction $D_{84}$ percentile on the assumption that fluvially transported gravel distributions are predominantly log-normal and $D_{84}$ represents a single standard deviation above the mean grain size. $D_{84}$ is a commonly used measure of coarse fraction grain size (Bunte et al., 2001; Inman, 1952) and has previously been a strong indicator of change in landscape boundary conditions and subsequent changes in sediment supply (e.g., Whittaker et al., 2010, 2011).

\subsection{Self-Similar Grain Size}

We evaluate whether the grain size distributions collected from each of the alluvial fan surfaces are self-similar. One test of the relative decay of the mean and standard deviations of surface grain size distributions is conducted by deriving the coefficient of variation $\left(C_{v}\right)$ for each downstream location. $C_{v}$ is defined below as the standard deviation $(\sigma)$ over the mean $(\bar{D})$ at each downstream spatial coordinate $x *$ :

$$
C_{v}=\frac{\sigma(x *)}{\bar{D}(x *)}
$$

If $C_{v}$ is approximately constant downstream, the grain size distributions are likely to meet the definition of self-similarity of Fedele and Paola (2007). We can demonstrate this by plotting the frequency density curves of self-similar grain size $(\xi)$ together to assess the degree of overlap. We binned all $\xi$ values for a surface into $0.5 \xi$ intervals, consistent with previous work (D'Arcy et al., 2016; Duller et al., 2010; Whittaker et al., 2010). As a means to statistically test for self-similarity, all $\xi$ distributions for each data set are cross-compared to test the coincidence of frequency distributions using the two-sample Kolmogorov-Smirnov test. This is more robust than a visual inspection of any apparent overlap (see Text S3). In this regard, frequency distribution curves should not have any systematic differences by way of skew or shift that may increase the vertical distance between the two sample cumulative frequency curves. The Kolmogorov-Smirnov test (K-S test) is a standard approach that has been applied by many previous authors to test the equivalency of several grain size distributions (Allen et al., 2017; Marcus et al., 1995; Strom et al., 2010) and is therefore an appropriate statistical tool to investigate whether distributions of self-similar grain size $(\xi)$ are indeed self-similar in actuality.

\subsection{Deriving Relative Mobility}

For self-similar $\xi$ distributions from the field, the Fedele and Paola (2007) self-similar solutions to relative mobility can be applied. To do this, an appropriate value of $J$ must be found for a given substrate frequency distribution of $\xi$. Evidence of self-similarity may suggest that a continuity of sediment transport and grain size fractionation exists from the catchment area to the alluvial fan and we can subsequently encapsulate this spatial variation using the constants $C_{1}$ and $C_{2}$ (see section 1.2). We employ a value of 0.55 for $C_{1}$ appropriate for our grain size fining observations (see sections 4.2 and 4.3), representing the lowest possible value within the $0.55-0.9$ range reported by sensitivity analysis (cf. Duller et al., 2010) and lower than 0.7 values of $C_{1}$ applied in previous field studies (cf. D'Arcy et al., 2016). The implicit assumption of this approach is that the gravel grain size distribution has not been affected by significant postdepositional modification and the extraction of grain size into stratigraphy is a function of accommodation space generation where tectonic uplift has remained stable through time. In finding a value for $J$ we are also invoking the presence of a transported grain size fraction that has not been stored in stratigraphy, inside which certain grain sizes are more 
likely to be present based on the $J$ ratio. The derivation of $J$ in this study will explore the sensitivity of relative mobility between alluvial fan surfaces that span a period over which sediment flux may have changed in response to glacial-interglacial transition (D'Arcy et al., 2016).

To provide some variability in between surfaces beyond the distributions of $\xi$, we generate a surface-specific $C_{2}$ value from the ratio of the local surface $C V$ value and $C_{1}$ (see Text S1). Using the fixed $C_{1}$ and variable $C_{2}$ values we can then produce an analytical form of $J$ in equation (3) to model an analogous and continuous substrate $\xi$ fraction using the Fedele and Paola (2007) self-similarity solutions that best matches the observed field distribution (see Text S1). The shape of the modeled substrate fraction can be tuned using the $a_{g}, b_{g}$, and $c_{g}$ constants in order to best fit the field-derived substrate fraction. In doing so, the best fit parameterization of $J$ can then be used to calculate the relative mobility of each value of $\xi$.

The best fit of $J$ is found using an automated iterative curve-fitting process in MATLAB that employs least squares approach with a trust-region-reflective algorithm (Coleman \& Li, 1993). The curve fitting systematically adjusts different $a_{g}, b_{g}$, and $c_{g}$ values such that a modeled grain size distribution curve correlates with a given field-derived distribution with the smallest difference between observed and modeled values. From these best fit values of $a_{g}, b_{g}$, and $c_{g}$ and the analytical solution to $J(\xi)$ (equation (3), we derive a continuous function of grain size relative mobility for a given alluvial fan surface. With our best fit relative mobility model for each fan surface, we can then reconstruct a dimensional grain size from model-predicted self-similar grain size $(\xi)$ using a rearrangement of equation (2) to produce equation (5), where dimensional grain size in millimeter $(D)$ is derived from the surface-averaged standard deviation $\left(\bar{\sigma}_{s}\right)$ and mean $\left(\bar{D}_{s}\right)$.

$$
D=\xi \bar{\sigma}_{s}+\bar{D}_{s}
$$

From this surface-averaged reconstruction of grain size, the mobility of different grain sizes on a given alluvial fan surface can be predicted from a locally derived parameterization of the $J$ function (equation (3)).

\section{Results}

\subsection{Fan Maps}

From aerial photography and field observation, distinct depositional surfaces were identified and mapped on each of the three alluvial fans, for which we were able to derive robust relative chronologies (Figure 2). Aerial photography of each fan (Figures 2a-2c) shows clear differences in surface coloration due to increased levels of desert varnish on older surfaces, which appear darker in contrast to younger surfaces. This effect is most pronounced on preserved areas that have not been altered by subsequent overland flow that reworks the surface layer. We identify both Holocene and late-Pleistocene surfaces on each of the alluvial fans in this study, with active Holocene surfaces ranging from the youngest, most active areas of the alluvial fans to various late-Pleistocene surfaces identifiable from surface varnishing, relative preservation of bar and swale morphology and terrace height. These alluvial fan chronologies are based on sedimentological distinctions that follow from previous Quaternary formations identified by many authors and are discussed in detail below (e.g., Bull, 1991; Frankel et al., 2007; Hooke \& Dorn, 1992; Klinger, 2002; Knott et al., 2005; Machette et al., 2008; Owen et al., 2011; Sohn et al., 2014).

We divide our fan surfaces further according to detailed sedimentological and geomorphic field observations. These details are shown in Figure 3, which displays a representative sample image of each fan surface (Figures $3 a-3 l$ ) with the relative stratigraphic order of fan terraces with maximum height difference taken near the fan apices (Figures 3m-3o). Contextual images of each of the fan surfaces are also available in the supporting information (Text S2). Most fan surfaces we observe show strong evidence of hydrological sorting, with imbricated clasts and preserved paleochannels on inactive surfaces as well as fresh deposits (cf. D'Arcy et al., 2016). Similarly, while many fan surfaces in Death Valley comprise a mix of debris flow and stream flow derived sediment (Blair, 1999c), we do not observe recent or relict debris flow levees on any of our fan surfaces. Subsequently, the active channels are characteristic of ephemeral channels with intermittent stream flow, with clear boundaries between channels and higher bar forms submerged during periods of flood and sheet flow. The localities where grain size was measured are traced along well-preserved fan surfaces; conversely, each fan exhibits portions that could not be attributed to a single definable surface due to reworking of older fan surfaces and/or mixing of sediment supply from adjacent catchments. These reworked or ambiguous areas are shown in gray in the fan maps in Figure 2 and tend to increase in area toward the fan toes, where the relative difference in height between surfaces decreases and the likelihood of sediment mixing increases. 

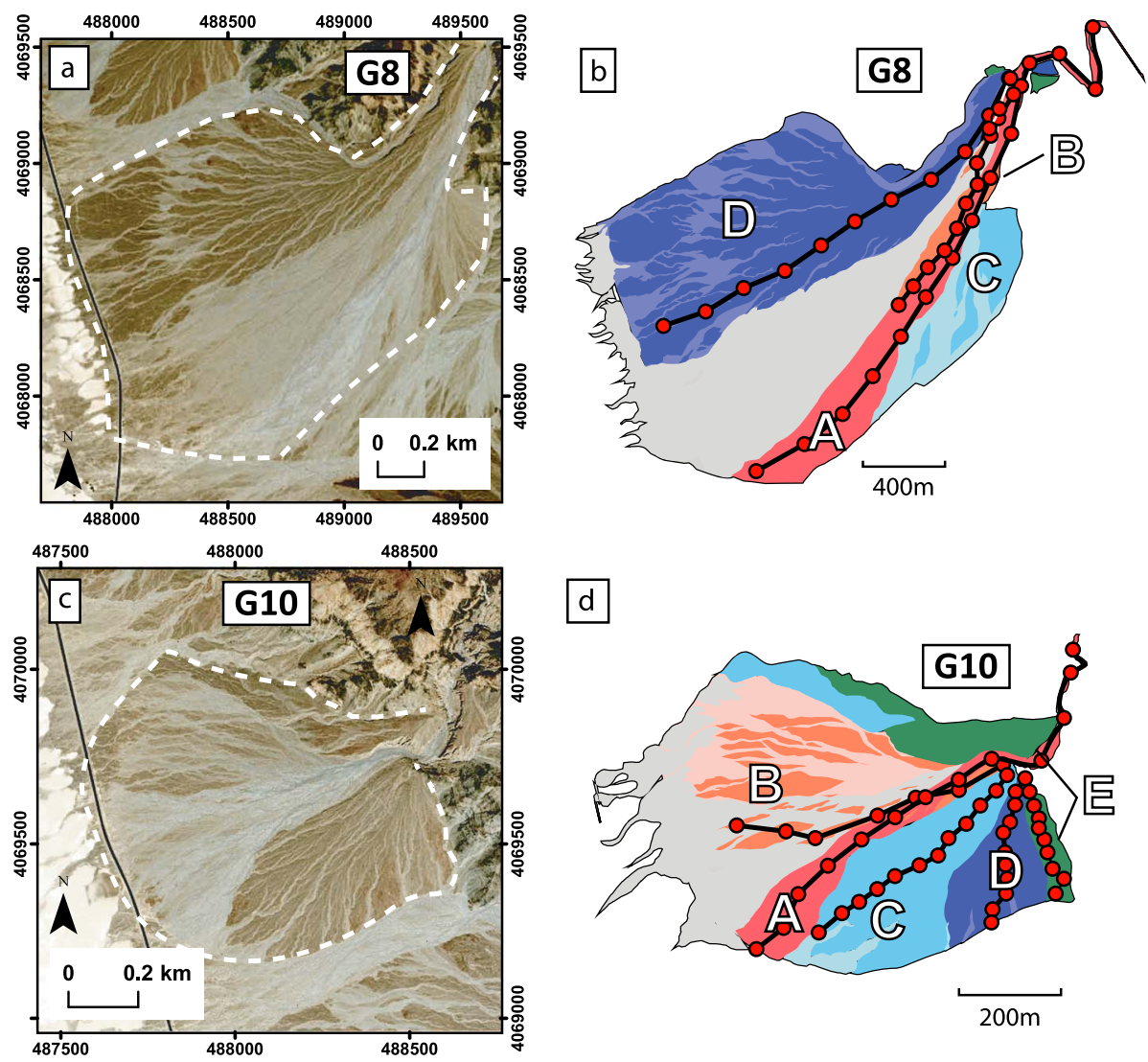

d
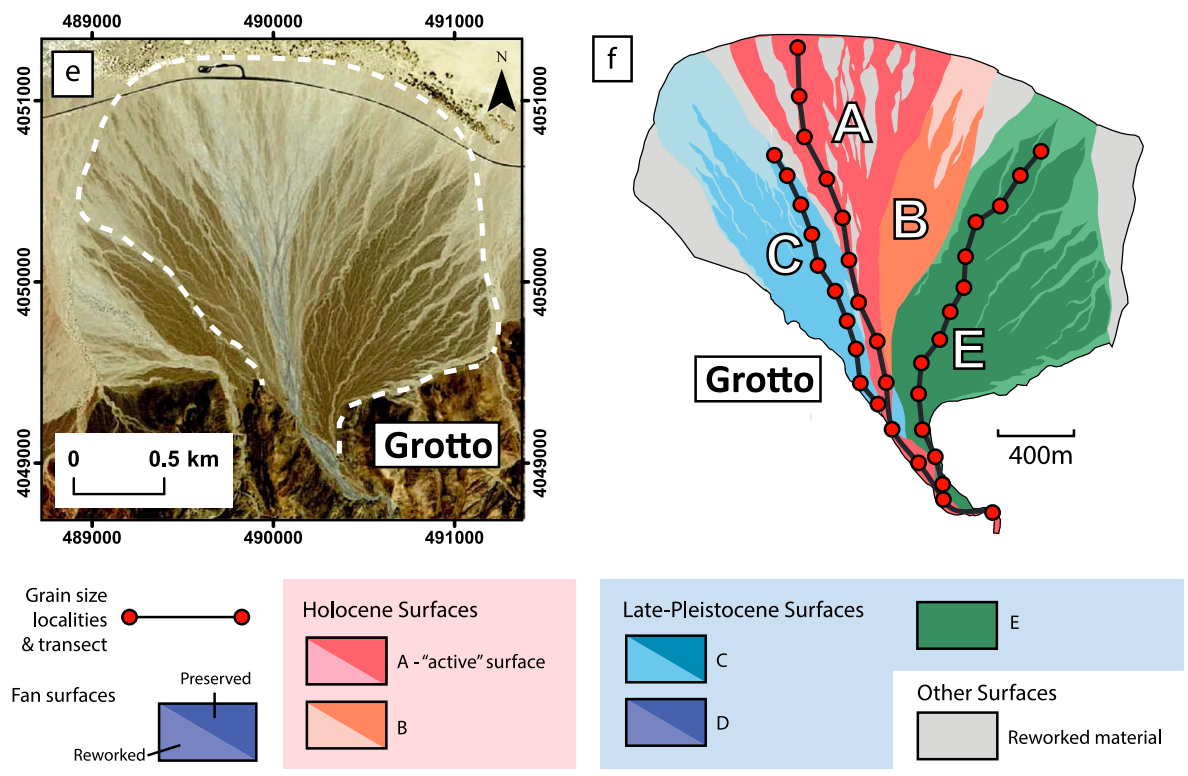

Figure 2. Aerial imagery and associated fan surfaces maps of study fans. The areal extent of fans is marked on aerial images by a white dashed boundary ( $a, c$, and e). Fan maps ( $b, d$, and $f)$ are colored to demarcate areal extents of continuous fan surfaces of different age $(A-E)$, with red/orange reserved for recent and Holocene surfaces $(A$ and $B$ ), and blue and green for late-Pleistocene surfaces (C-E). Lighter hues denote areas where material has been partially reworked by overland flow, with darker hues marking areas of better or complete surface preservation. Gray areas denote areas of extensive sediment reworking that prohibits accurate surface identification. Red circles along black lines denoting the length of fan surface transects mark locations of grain size measurement. 


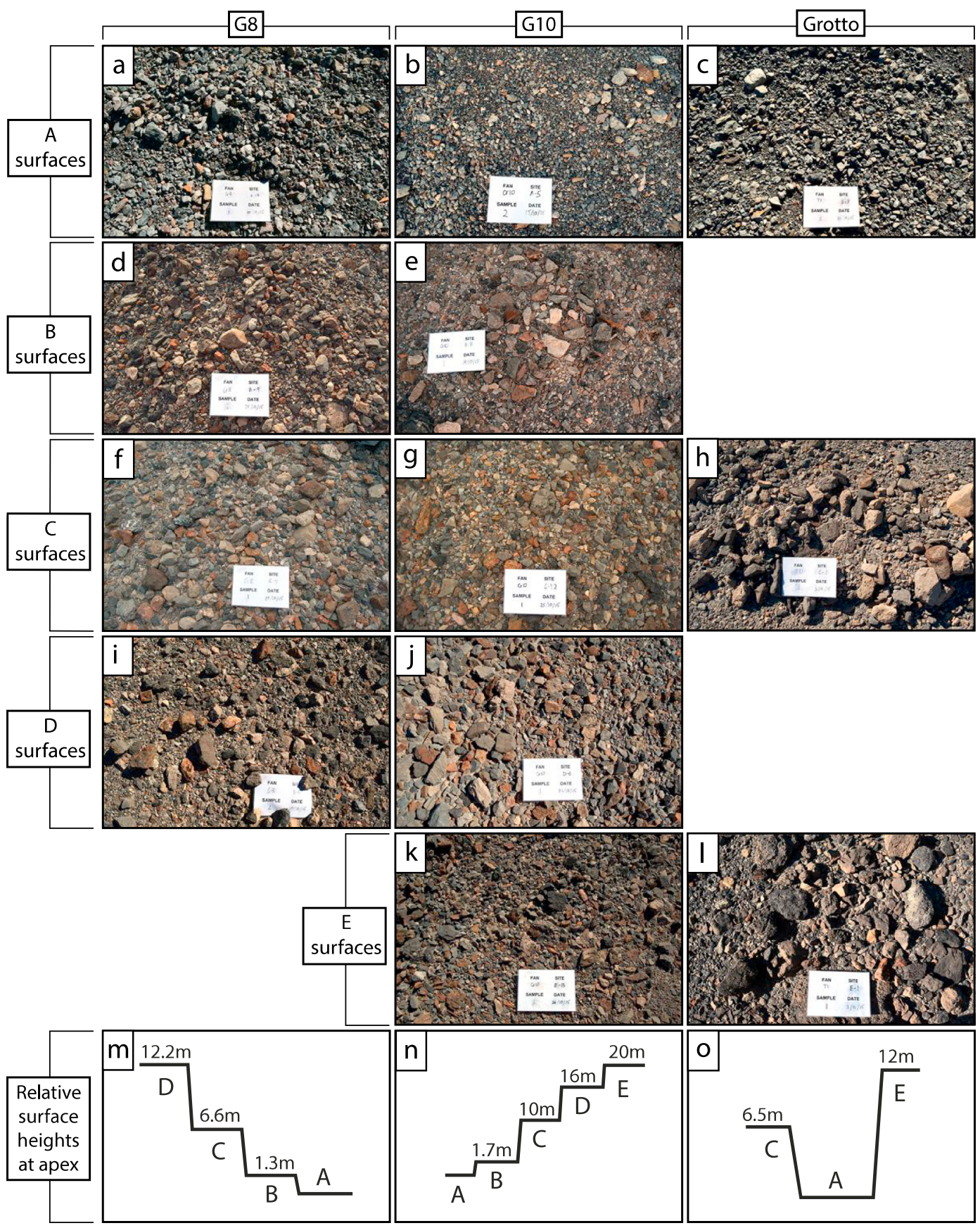

Figure 3. (a-j) Photographic samples of alluvial fan surfaces comparing changes in surface morphology, with increasing levels of varnishing in the older alluvial fan surfaces $C, D$, and $E(f-j)$ relative to the youngest Holocene $A$ surface units $(a-c) .(m-o)$ Schematic diagrams of maximum fan terrace heights relative to the active channel (A surface). Fan heights were measured at the fan apex, where the relative height differences are at maximum.

Within the Holocene, two units were identified; the active or " $\mathrm{A}$ " surface traced along the path of recently transported material commonly referred to as the Q4 surface by several authors (e.g., Hunt \& Mabey, 1966; Klinger, 2002; Knott et al., 2005; Owen et al., 2011), and a prevalent 1- to 2-m higher terrace of marginally varnished and partially cemented material that we classify as "B." A surfaces were identified based on evidence of recent flow, such as fresh bar forms, loose stacks of imbricated cobble clasts, and the overall poor consolidation of sediment (Figures $3 a-3 c$ ). B surfaces show a preserved bar and swale morphology where clasts have often retained their original orientations and imbricated stacking arrangement. The $B$ surface is often a discontinuous surface, the remnants of which are commonly islands within the active depositional lobe or small 
terraces immediately adjacent to surface A. We interpret B surfaces as abandoned Holocene Q3b-c units ranging from 2-10 ka in age, in agreement with similar surfaces observed on other Death Valley fans (Frankel et al., 2007; Frankel \& Dolan, 2007; Klinger, 2002; Owen et al., 2011; Sohn et al., 2007, 2014; Figures 3m-3o). Given the proximity of $A$ and $B$ surfaces, a moderate degree of intermixing across the fan surfaces has sometimes occurred, often where terrace heights are within the range of floods or overland flow. Through local comparison, the B surface material shows a slight degree of desert varnish, with stronger material consolidation within the bed compared to $A$ (Figures $3 \mathrm{~d}$ and $3 \mathrm{e}$ ), suggesting postdepositional cementation of clasts. The $B$ surfaces do not show any evidence of desert pavement formation and are mostly pristine above 1-m elevations where the abandoned bar and swale morphology is visibly intact with a clear lack of subsurface aeolian deposits visible from side cuts. We refer the reader to the contextual surface and side cut photographs in the supporting information (Figures S2-2, S2-6, S3-1, and S3-2) that show typical surface and side cut localities on the B surface.

In the field, fan terraces higher than B surfaces were marked conspicuously at the fan apex by a 5- to 8-m difference in terrace height (Figures $3 m-30$ ). We identify these terraces as surface $C$, which show a discernably greater degree of desert varnishing than younger $A$ and $B$ units, albeit with clear remnants of bar and swale morphology, no subsurface aeolian deposit and continuity between surface and subsurface gravel material (Figures $3 \mathrm{f}-3 \mathrm{~h}$, and supporting information Figures S2-3, S2-7, and S2-11). For these surfaces it was still necessary to measure distributions on both coarser patches of bar material and the finer material of former swales areas to capture the total gravel grain size distribution. The general relief of $C$ surfaces is well preserved, with coarse bar-like areas with finer grain sizes within swale-like depressions, akin to the younger B or A surfaces except for a distinct lack of preserved clast imbrication. The $C$ surface represents the first surface of a series of higher terraces that constitute material that is likely to be older than $11 \mathrm{ka}$ in age or otherwise representative of late-Pleistocene conditions, with the progressively older $D$ and $E$ surfaces composed of material deposited earlier in the Pleistocene. In this study we view our B-C surface boundary as the late-Pleistocene-Holocene transition, with the $C$ surface as the latest Pleistocene unit.

$D$ and $E$ surfaces are moderately varnished, with exposed clast surfaces showing a clear varnished coloration compared to concealed surfaces that preserve the original clast color. Material on the D surfaces is cemented by a muddy matrix, revealing closely packed material underneath. The $D$ surfaces are, however, still fractionated on the surfaces, with discernably coarser patches of material that follow as the next stage of the gradual diffusion of relict bar and swale morphology observed on the younger $C$ surface. The $D$ surface is most easily identified as having a combination of moderate to heavy clast varnishing with the last remnants of original bar and swale morphology, which still require a series of separate coarse and fine fraction clast measurements (Figures $3 \mathrm{i}-3 \mathrm{j}$ and supporting information Figures S2-4 and S2-8). The E surfaces, the next and final surface above the D surface, are identified based primarily on comparative lack of preserved bar and swale morphology, often experiencing secondary topographic development as small gullies or runnels incise into the surface. E surfaces show a greater degree of subdued depositional morphology and evidence of sporadic rock fracture with interlocking smaller angular clasts. E surfaces also display a thin layer of fine material beneath, suggesting more developed desert pavement, albeit with visible gravel clasts present underneath the superficial layer (Figures 3k and 31 and supporting information Figures S2-9 and S2-12), the importance of which is discussed in detail later in this paper.

Although we have a robust relative age chronology for surfaces $C, D$, and $E$, and there is little doubt they are late Pleistocene in age, we do not have absolute dates for these surfaces. However, combining our observations with the sedimentological criteria and chronologies of previous workers (e.g., Bull, 1991; Frankel et al., 2007; Frankel \& Dolan, 2007; Hooke, 1972; Hooke \& Dorn, 1992; Klinger, 2002; Knott et al., 2005), we can put broad timings on the history of deposition. Specifically, we attest that the $C$ surface unit corresponds broadly to an early Q3 surface, with some varnishing but clear preservation of bar and swale morphology, otherwise identified by several previous studies across Death Valley as a latest Pleistocene surface that may latterly represent the transitional unit into the early Holocene, with ages ranging from 7 to 24 ka (Frankel et al., 2007; Klinger, 2002; Sohn et al., 2014) potentially also correlating with the 12- to 30-ka Qay surface by Machette et al. (2008). Earlier Pleistocene surfaces D and E are likely to range within the well-documented Q2a-c unit that encompass definitive late-Pleistocene deposits with ages of 35-85 ka (Frankel et al., 2007; Klinger, 2002; Knott et al., 2005; Owen et al., 2011) or additionally corresponding to the identified 40- to 100-ka Qai surfaces by Machette et al. (2008) on the eastern flank of the Panamints. D surfaces show retention of some diffused 
bar and swale morphology and has an equivalent degree of desert varnishing to surface $E$ (see supporting information Figures S2-4 and S2-8), broadly correlating with the dated and mapped circa 70 ka surfaces (Q2C) $15 \mathrm{~km}$ to the north (Frankel et al., 2007).

Using the morphological distinctions of Frankel and Dolan (2007), the loss of surface roughness from the original fluvial bar and swale morphology as a product of lateral clast migration occurs before $70 \mathrm{ka}$. The oldest preserved $\mathrm{E}$ unit surfaces are smooth with secondary incision, particularly toward the fan toes, which suggests that these surfaces are Pleistocene in age, with a lower age bound of $70 \mathrm{ka}$ (Q2c; Frankel et al., 2007). The only upper age control on E surfaces is a lack of highly diffused convex upward hillslope morphology, observed to develop on surfaces older than 100 ka (Dühnforth et al., 2017; Frankel \& Dolan, 2007), surfaces that subsequently could encompass the previous Eemian interglacial period 130-115 ka. Given this sole morphological constraint, we refrain from direct correlation of E surfaces to a single gravel subunit of Q2 but otherwise attest that $E$ is likely to be $70-100$ ka in age.

In terms of spatial fan surface preservation, the initial fan unit thickness, the occurrence of fan lobe avulsion, and the degree of intermittent channel incision all determine the preservation of fan surface area. The most laterally extensive surfaces are older late-Pleistocene surfaces (C, D, and E). Active (A) and older Holocene (B) surfaces are less laterally extensive and are confined to incised channels cutting into the $C, D$, and $E$ units. This incision and confinement of active Holocene fan units is observed on every fan, with the greatest levels of incision observed closest to the catchment outlet at the fan apex, with terrace heights ranging from 5 to 20 $m$ in height from active channel to late-Pleistocene terraces (Figures $3 m-30$ ). Fresh incisional cuts provide an effective location to test the equivalency of surface versus subsurface grain size distributions. We conducted a series of Wolman point counts on both the surfaces and adjacent side cuts and found no systematic difference between them (see Text S3). These comparison studies demonstrate that the surface measurements are, in effect, capable of providing a proxy of the approximate long-term deposited gravel distributions. On G8, a large portion of the fan is reworked (Figure $2 b$ ) where Holocene A and B surfaces intermingle and there is significant evidence of recent flow deposits mixed within the slightly varnished $B$ surface.

\subsection{Surface Grain Size Variation}

A comparison of cumulative grain size distributions from each locality is shown in Figure 4. This shows a clear disparity in sediment caliber between fan surfaces A and B, of Holocene age (red curves), and fan surfaces $C$, $D$, and $E$ of late Pleistocene age (black curves). In particular, Figures 4 a- $4 c$ show a pronounced skew in grain size, with late-Pleistocene-correlated surfaces having curves shifted farther toward larger grain sizes; the difference greatest when comparing coarse fraction $\left(D_{84}\right)$. This pattern is visible on each of the three alluvial fans, with the lowest magnitude shift in grain size on the G8 fan (Figure 4a). By comparison, the G10 fan (Figure 4b) has the clearest difference between Holocene and late-Pleistocene grain size curves, with little overlap between the two series of curves and approximately $50 \%$ larger $D_{84}$ grain sizes (marked by the black dashed line) with the Grotto Canyon fan (Figure 4c) showing an equivalent pattern. The spread of grain sizes is dependent on the percentile we compare and is greatest for grain sizes above the $D_{50}$, where the cumulative frequency curves diverge. We anticipate that sensitivity to any time-dependent changes in grain size is most evident in the $D_{84}$ grain size.

Figure 5 shows a limited downstream fining of grain size from fan apex to fan toe when fitted with a Sternberg fining law (Figures 5a-5c; Sternberg, 1875), with no downstream change in mean grain size apparent on Holocene surfaces (A and $B$ ) and limited fining on surfaces that correlate to the late Pleistocene $(C, D$, and E). On each fan, late-Pleistocene-correlated grain size is consistently coarser than Holocene surfaces for the majority of each transect. Furthermore, grain size is stable (within 1 standard deviation) across each fan transect such that the mean and other statistical grain size metrics are appropriate approximations for fan surfaces as a whole, especially for Holocene surfaces. Given that no coarse material can bypass these alluvial fan systems (e.g., toecutting by an axial river), these combined grain size distributions essentially constitute spatially averaged long-term extracted substrate distributions from the input feeder channel.

When we combine surface grain size into a single distribution, the total grain size spread on a surface can be visualized as box-whisker plots (Figures $4 d$, e and f), showing the differences in median $\left(D_{50}\right)$ and coarse-fraction $\left(D_{84}\right)$ grain sizes between surfaces, where $D_{50}$ is the red bar within a box that encompasses the spread in grain sizes between the 25th and 75th percentile, and the $D_{84}$ a black line connecting individual surfaces to illustrate a trend. On each fan, total surface $D_{84}$ and $D_{50}$ are consistently larger in 

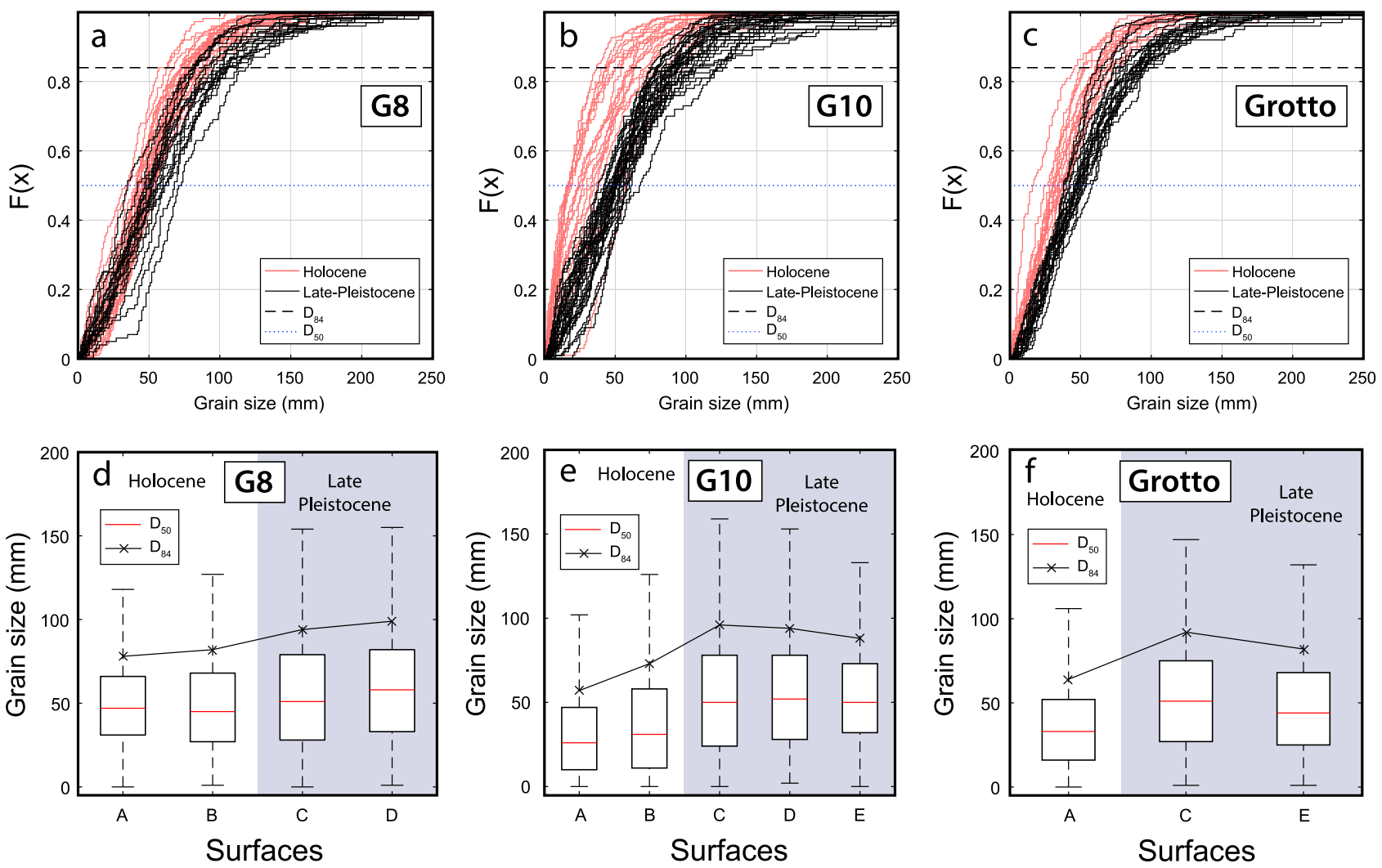

Figure 4. $(\mathrm{a}-\mathrm{c})$ Normalized grain size cumulative frequency curves of grain size measured on each fan, colored binned according to the age of the fan surface (red for Holocene surfaces, black for late-Pleistocene surfaces). Each individual curve represents a single grain size distribution that measured a locality using the Wolman point count method. Median grain size $\left(D_{50}\right)$ values intersect the blue dotted line, with coarse fraction $\left(D_{84}\right)$ grain size values intersecting the black dashed line. $(d-f)$ Box and whisker plots showing total variation in grain size measurements for each surface (e.g., A-E) per alluvial fan. Plots with a white backdrop are Holocene in age, while plots with a blue backdrop are late Pleistocene in age. Boxes mark range of grain size values between $D_{25}$ and $D_{75}$ grain sizes, with the whiskers encompassing $95 \%$ of total grain sizes. Red lines mark the $D_{50}$ or median grain size, while a black line marks surface variation in $D_{84}$.

late-Pleistocene-correlated surfaces compared to the Holocene. Late-Pleistocene-correlated surfaces also show a larger spread in grain size marked by the extents of the "whiskers" that encompass the $95 \%$ confidence interval of measured grain size.

Limited variation is observed in $D_{50}$ grain size between surfaces for fan G8 (Figure $4 \mathrm{~d}$ ), with surface D only $5-10$ $\mathrm{mm}$ coarser than the active Holocene (A). Holocene A and B surfaces on G8 (Figure 4d) are 30-40\% coarser than counterpart surfaces on $\mathrm{G} 10$ and Grotto (Figure $4 \mathrm{e}$ and $4 \mathrm{f}$ ), showing little difference to late-Pleistocene surfaces. Across all fans, late-Pleistocene-correlated surfaces $(C, D$, and $E)$ occupy a similar range of $D_{50}$ grain size of approximately $50 \pm 5 \mathrm{~mm}$ along the long axis.

$D_{84}$ grain size shows a greater shift between $C$ and $B$ surfaces on each fan, with a drop of $17 \%$ (16 mm) on G8 (Figure 4d), 40\% (39 mm) on G10 (Figure 4e) and 30\% (28 mm) on Grotto (Figure 4f) when measuring the difference in $D_{84}$ between the Pleistocene and Holocene. The magnitudes of $D_{84}$ grain size change between proposed Holocene-Pleistocene surfaces exceed any potential compounded measurement error between Wolman point counts (see Text S3). Compared with finer grain size fractions, the coarse material on fan surfaces undergoes a greater change in grain size from late Pleistocene to Holocene compared to the change in $D_{50}$ grain size. Additionally, $D_{84}$ trends also show disparity within the late Pleistocene, with the oldest measured units (E surfaces) 10-20 mm finer than the latest Pleistocene (C surfaces) for fans G10 (Figure 4d) and Grotto (Figure 4f), where the E surface could be identified and measured. This shows that across two fans grain size is not coarsening uniformly relative to the age of the fan surface, an effect we would expect to observe if grain size had been modified by the selective removal of fines by overland flow. It is not possible to infer the same relationship on $\mathrm{G} 8$ where the $\mathrm{E}$ surface is absent. 

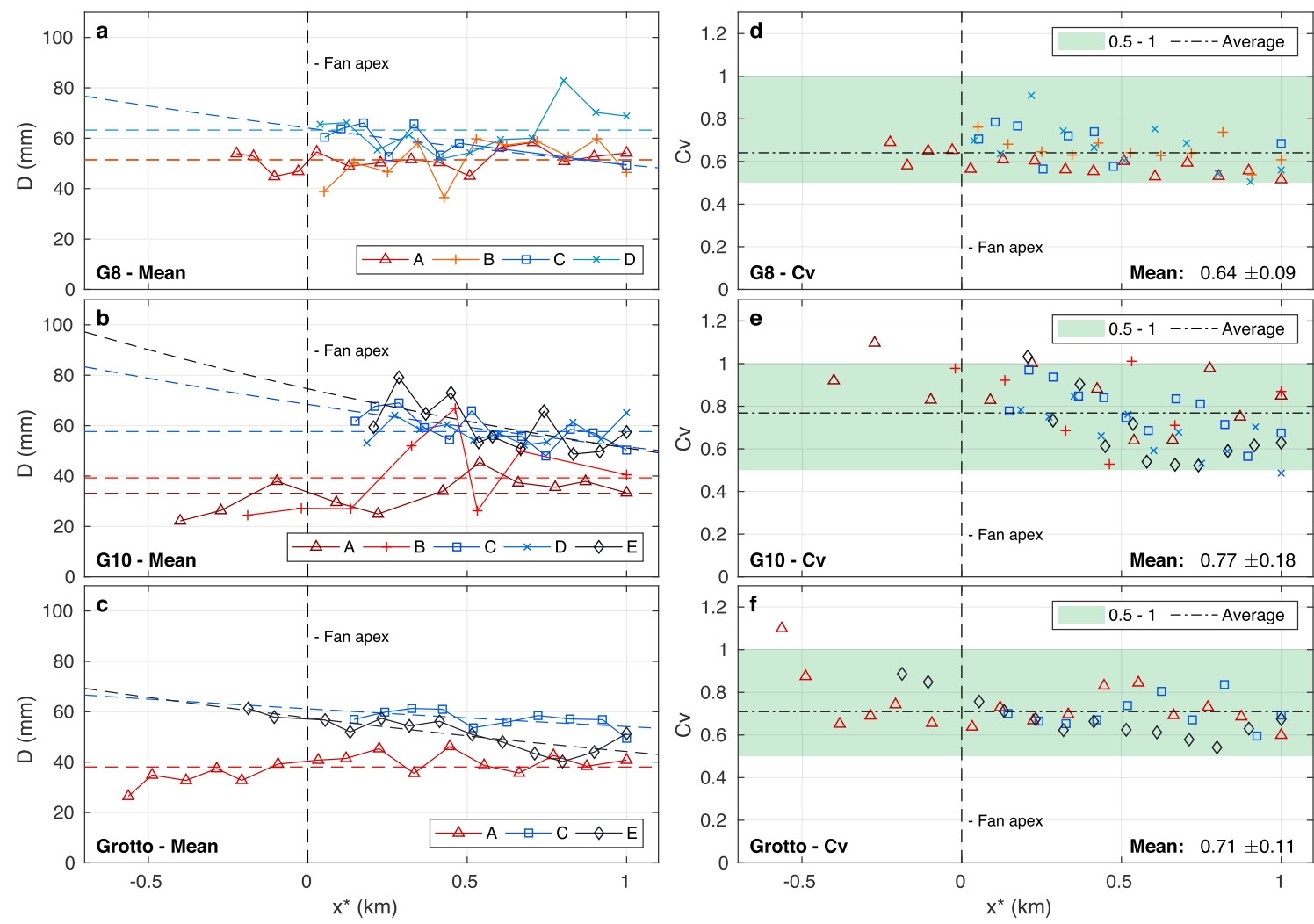

Figure 5. $(\mathrm{a}-\mathrm{c})$ Fan to apex-relative downstream change in mean grain size $(\mathrm{mm})$ per fan surface transect. Distances $\left(\mathrm{x}^{*}\right)$ are normalized to the length of the fan, where 0 is the fan apex and 1 the fan toe, with negative distances marking locations upstream of the fan apex. Each point represents a single locality where grain size distributions were captured according to the Wolman point count method. Fan surfaces are distinct in terms of color and symbology, with red/orange for Holocene surfaces, and blue/black for late-Pleistocene surfaces. Each fining trend is fitted with a Sternberg fining law with a positive exponent (dashed lines). $(d-f)$. Fan-apex-relative downstream change in coefficient of variation (see above for symbology), with each point representing local coefficient of variation calculated from grain size measurements at a locality.

We observe that $C_{V}$ is approximately stable down each fan transect (Figures $5 d-5 f$ ), with values of about $0.5-1$. Ten out of 12 surfaces show no statistical trend in $C_{v}$ downstream, with the exception of late-Pleistocene surface $C$ on G10 (Figure 5e) and surface $E$ on Grotto (Figure $5 f$ ) where $C_{v}$ varies from approximately 0.8 to 0.55 down transect, albeit with some scatter. From the relative stability of $C_{v}$ across the surfaces, with averages across fans of $0.65-0.8 \pm 0.1$, we approximate to the first order that the mean and standard deviation of fan surface grain size is inherently stable or decaying at the same rate when fining is occurring, with no observed change through time.

\subsection{Self-Similar Grain Size and Best Fits}

Surface-specific self-similar transformations of grain size are produced using equation (2), from which we test how statistically similar self-similar grain size distributions are in space (between sites) and in time (between fan surfaces) or between individual catchment-fan systems. Specifically, comparison of unmodified and self-similar grain size cumulative frequency curves between individual sites (see Text S4), surfaces (Figures 6a and $6 \mathrm{~b}$ ) and fans (Figures $6 \mathrm{c}$ and $6 \mathrm{~d}$ ) show that regardless of observation scale, the spread in distributions collapses when grain size is transformed into a self-similar form ( $\xi$ ). Using the two-sample Kolmogorov-Smirnov test we show that self-similar grain size distributions for individual fan site measurements have an $87 \%$ pass rate, an improvement of $35 \%$ compared to unmodified grain size distributions, which is expected for surfaces with stable down transect grain size and standard deviation (see Text S3 and Figure S3-4). Between surfaces across all observed fans, self-similar grain size also shows a pass rate of $89 \%$ on average, while cross-compared, unmodified surfaces only exhibit an initial 6\% pass rate (see Text S3 and Figure S3-5). These tests show that the self-similar grain size transformation appears to be statistically robust and effective in collapsing grain size data from alluvial fan surfaces in Death Valley of different age, feeder catchment, and total grain size distribution. 

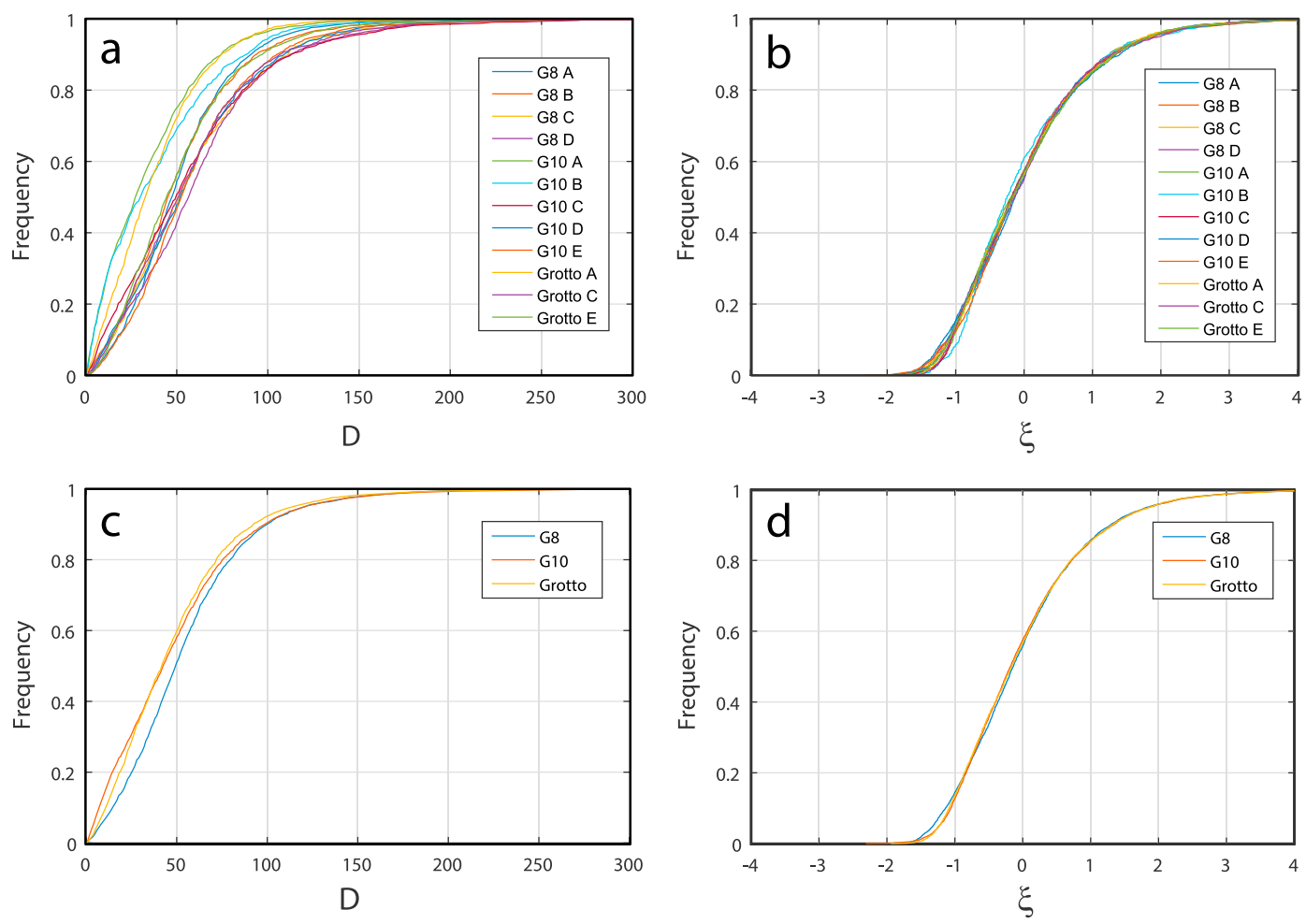

Figure 6. Combined cumulative frequency curves for fan surfaces and entire fans. Plots (a) and (c) are cumulative frequency plots for unmodified grain size in millimeters $(D)$ for each fan surface (a) and a total combined grain size distribution for each fan (c). Counterpart plots for self-similar grain size ( $\xi$ ) (b and d) show the collapse of the unmodified cumulative frequency curves onto a single general cumulative frequency function with $\xi=0$ at approximately the 60th percentile. Plot (b) shows the self-similar cumulative frequency curves for individual fan surfaces and plot $(d)$ the self-similar grain size cumulative frequency curves for entire fans.

For each surface, self-similar grain size $(\xi)$ distributions can be discretized into probability density plots (Figure 7). From the spread of $\xi$ values for a given bin of 0.5 , the mean is taken to produce a single plot of average $\xi$ values connected by a black line, the shape of which can act as an a priori test of intersurface and interfan self-similarity after Fedele and Paola (2007). The comparative overlap of average $\xi$ values of frequency suggests self-similarity between fan surfaces. Figure 7 shows that average $\xi$ probability density curves collapse onto near identical curves with peaks ranging from $\xi$ values of -1 to 0 at a frequency of 0.2 to 0.3 ; each point represents a frequency of a given $\xi$ size at a location. The cloud of $\xi$ frequencies is plotted to highlight the variance in frequencies across a given surface and how the average curves approximate the surface as a whole.

We fit the nonlinear dimensionless relative mobility parameter $J$ (equation (3); Fedele \& Paola, 2007) to the average $\xi$ curves using least squares regression to produce best fit analytical solutions for each surface (see Text S5) under the assumption of no postdepositional modification (see sections 4.1 and 5.2). One important consideration was the choice of an appropriate $C_{1}$ value that encapsulates the relative partitioning of the gravel supply produced by the systematic down-system change in standard deviation (see Text S1). Given that we observe limited downstream fining in our alluvial fan transects (Figures $5 a-5 c$ ), we choose a $C_{1}$ of 0.55 , in the lower bracket of potential $C_{1}$ values that have been previously reported to vary between 0.55 and 0.9 (Fedele \& Paola, 2007). Using $C_{1}$ at 0.55 , field $C v$ and derived $C_{2}$ values (see section 3.4 ) the model sensitivity outcomes show very good agreement within $95 \%$ confidence, with greatest variation in curve fits seen in the Holocene surfaces A and B of G10 (see Figures S5-1e and S5-1f).

Per surface, $a_{g}, b_{g}$, and $c_{g}$ parameters also show good agreement when compared between surfaces (Figures $8 \mathrm{a}-8 \mathrm{c}$ ), with $a_{g}$ values predominantly falling between 0.1 and $0.35, b_{g}$ values between 1.5 and 2.7, and $c_{g}$ values between 0.15 and 0.5 . Deviations away from these values are seen on the lower model certainty the $\mathrm{G} 10$ Holocene $\mathrm{A}$ and $\mathrm{B}$ surface curves, with higher $a_{g}$ values and lower $b_{g}$ compared with the remaining 10 surfaces. The values in this study are comparable with the best fit parameters derived from the recent study 

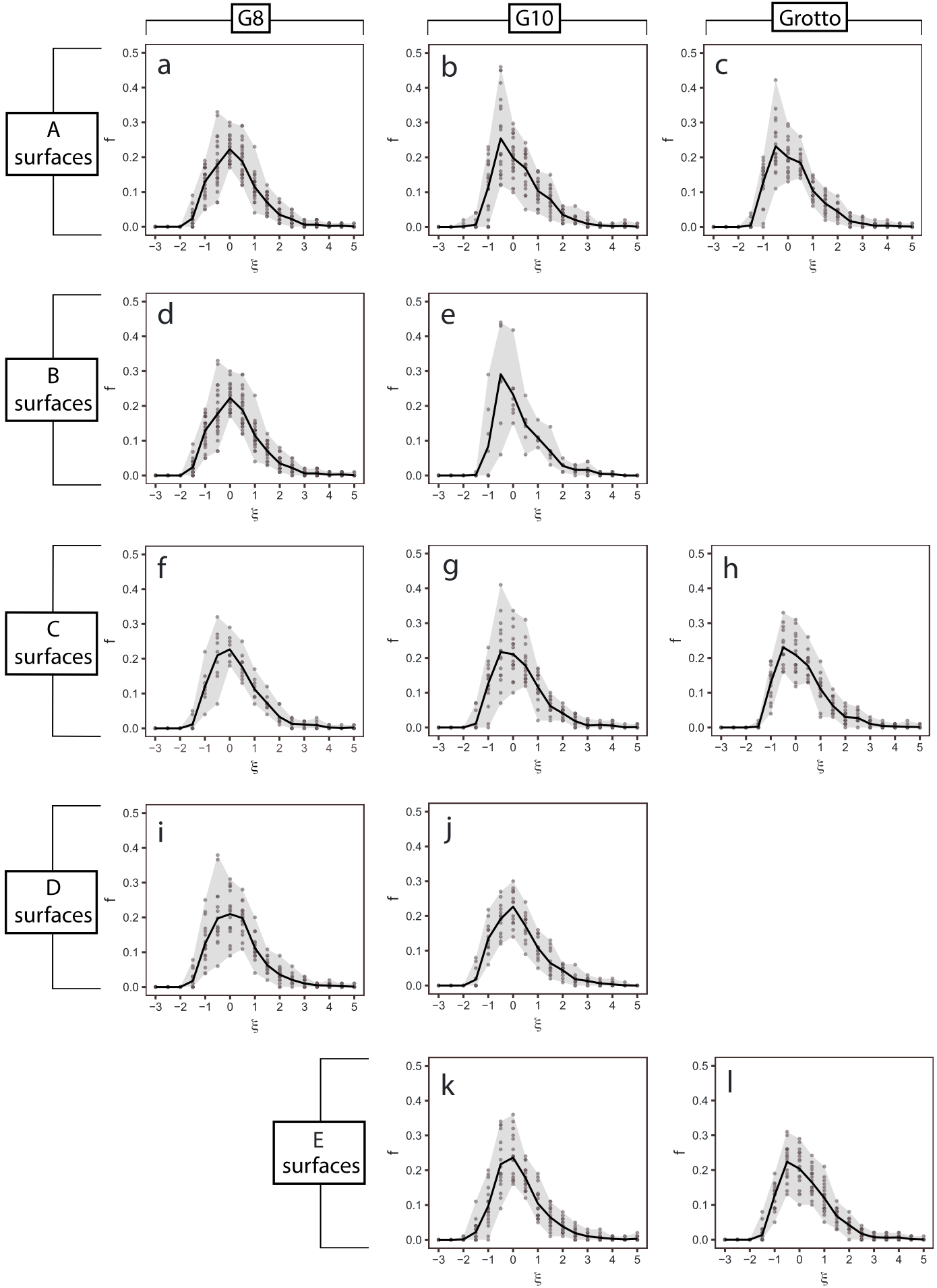

Figure 7. Self-similar grain size distributions for each fan surface; plots $a, d$, f, and i show G8 surfaces $A, B, C$, and D, respectively, plots b, e, g, j, and k show G10 surfaces A, B, C, D, and E and plots $c$, h, and I show Grotto Canyon surfaces A, $C$, and E. Gaps in the grid represent a lack of surfaces measured or present on the fan that correlate to letter designation. Each plot shows a frequency-density curve of the self-similar grain size variable $\xi$ constructed from the average values for each bin of 0.5 . All $\xi$ measurements for every locality are plotted together to assess the degree of variation about the mean value calculated for every $\xi$ bin size, plotted as the solid black line. The spread in $\xi$ values for each bin size is marked by the extent of a gray envelope. Each point on every plot denotes the frequency of a given self-similar grain size $(\xi)$ for a locality on the surface. 

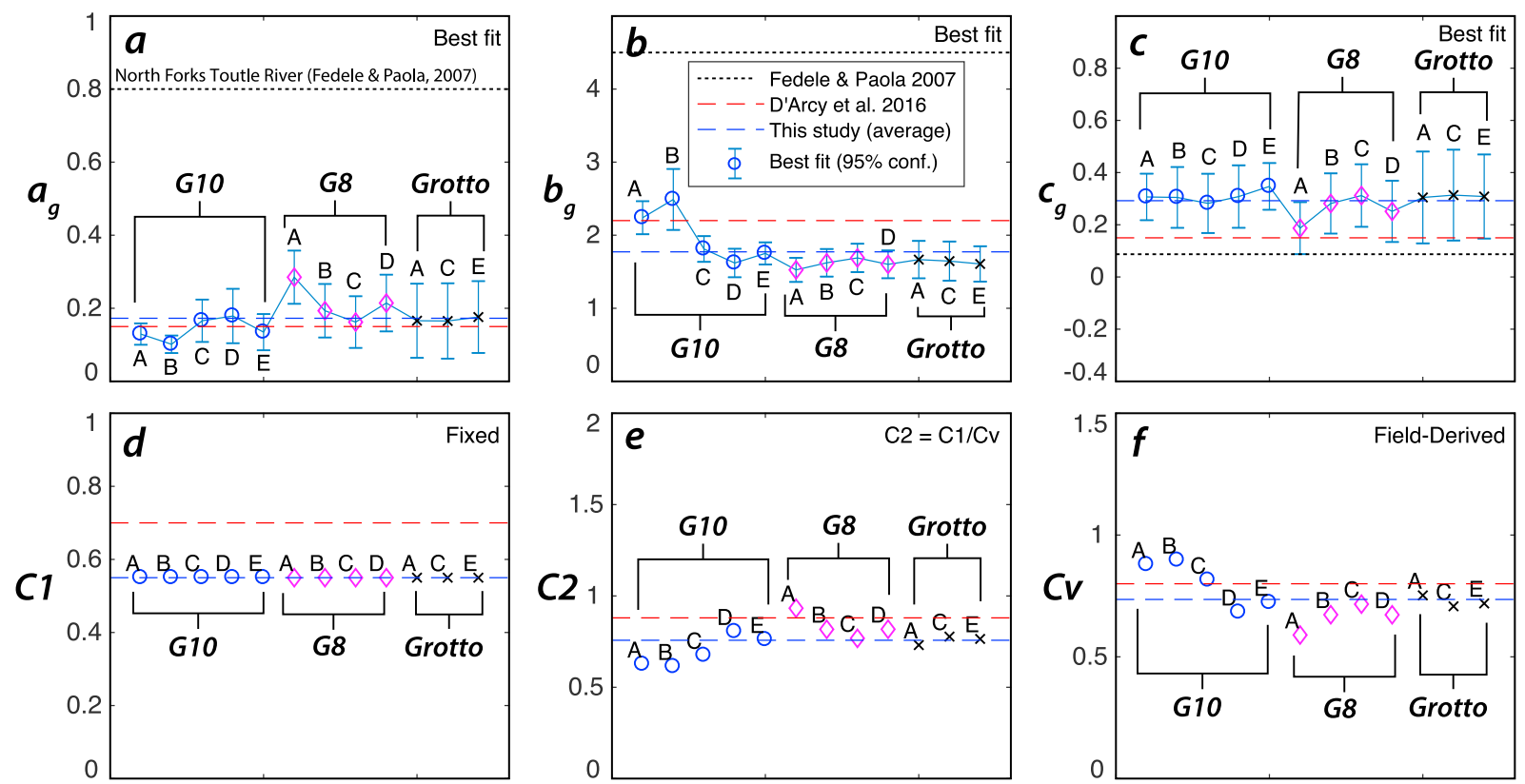

Figure 8. Model fit parameters from per surface iterative curve fitting. Panels (a) - (c) show the per-surface best fit values for $a_{g}, b_{g}$, and $c_{g}$ with error bars denoting the possible variation within $95 \%$ confidence. Blue dotted lines mark the average value for each parameter from this study, red lines denoting the values used by previous authors D'Arcy et al. (2016) using the Fedele and Paola (2007) self-similarity solutions on alluvial fans grain size in Death Valley. Black dashed lines denote the values used by Fedele and Paola (2007), for their pilot analysis of the North Fork Toutle River, Washington. (d) Fixed $0.55 C_{1}$ values. (e) $C_{2}$ values derived from ratio of $C_{1}$ and $C_{v}$. (f) Field-derived $C v$ values from the mean values across each surface.

by D'Arcy et al. (2016) of two alluvial fans approximately $17 \mathrm{~km}$ northwest along strike of the Grapevine fault from G8 and G10. In that study, D'Arcy et al. (2016) applied a visual best fit approach to self-similar grain size distributions and derived a value of 0.15 for $a_{g}$ and 2.2 for $b_{g}$ (red dashed lines) that sit within the spread of values in this study. Both sets of alluvial fan values are in contrast with the parameters used in the Fedele and Paola (2007) pilot study (following the observations of Seal \& Paola, 1995) from the North Fork Toutle River (black dashed lines). We use sample distributions from the North Fork Toutle River used in Fedele \& Paola, 2007, Figure 9), originally from bulk grain size distribution collected over river cross sections (Seal \& Paola, 1995) to produce best fit parameters for $J(\xi)$ using a $C_{V}$ value of 0.7 and $C_{1}$ of 0.75 . The North Fork Toutle River is a perennial braided river system in Washington State, USA from which we derive the values; $a_{g}=0.1$, $b_{g}=4.5$, and $c_{g}=0.08$ (see Text S5). Compared to Seal and Paola (1995) we produce different fits derived for alluvial fan grain size distributions in Death Valley, with smaller $a_{g}$ and $b_{g}$ values in agreement with the values fit by D'Arcy et al. (2016) and larger values for $c_{g}$ (Figures $8 \mathrm{a}-8 \mathrm{c}$ ). These values are found to be sensitive to the kurtosis of self-similar grain size distributions, with larger differences between $a_{g}$ and $b_{g}$ providing better fits for grain size distributions with smaller, narrower peaks. The magnitude of both $a_{g}$ and $b_{g}$ is found to have a control on position of the modal $\xi$ value (or peak) of the produced $\xi$ distribution, with greater values of $a_{g}$ and $b_{g}$ moving the peak to larger values of $\xi$. As such, the difference between $a_{g}$ and $b_{g}$ values for the North Fork Toutle River compared to the Death Valley fans (Figures $8 \mathrm{a}$ and $8 \mathrm{~b}$ ) reflects a narrower grain size distribution (see Text S5). The value of $c_{g}$ sets the maximum asymptotic value of $\mathrm{J}$, which when greater than 0 , implies a degree of mobility for all present grain sizes.

The field-derived values of $C_{v}$ (Figure 8f) are comparable to the recent work by D'Arcy et al. (2016; red dashed line), who derive values of $C_{v}$ equivalent to the average $C_{v}$ from surface grain size distributions measured in this study (blue dotted line) within statistical error. Given the limited downstream fining we observe, our application of a lower 0.55 value of $C_{1}$ compared to D'Arcy et al. (2016, who apply a value of 0.7) combined with our larger $C_{v}$ values produces a lower series of $C_{2}$ values (Figure 8e).

\subsection{Modeling Relative Mobility}

Using equation ( 3 ) and best fit solutions for $J$, we produce continuous relative mobility functions for self-similar grain size $(\xi)$ for each alluvial fan surface (Figures 9a, 9c, and 9e). We model predicted changes in grain size mobility between Holocene and late-Pleistocene conditions as recorded in our fan surfaces, a timescale over 

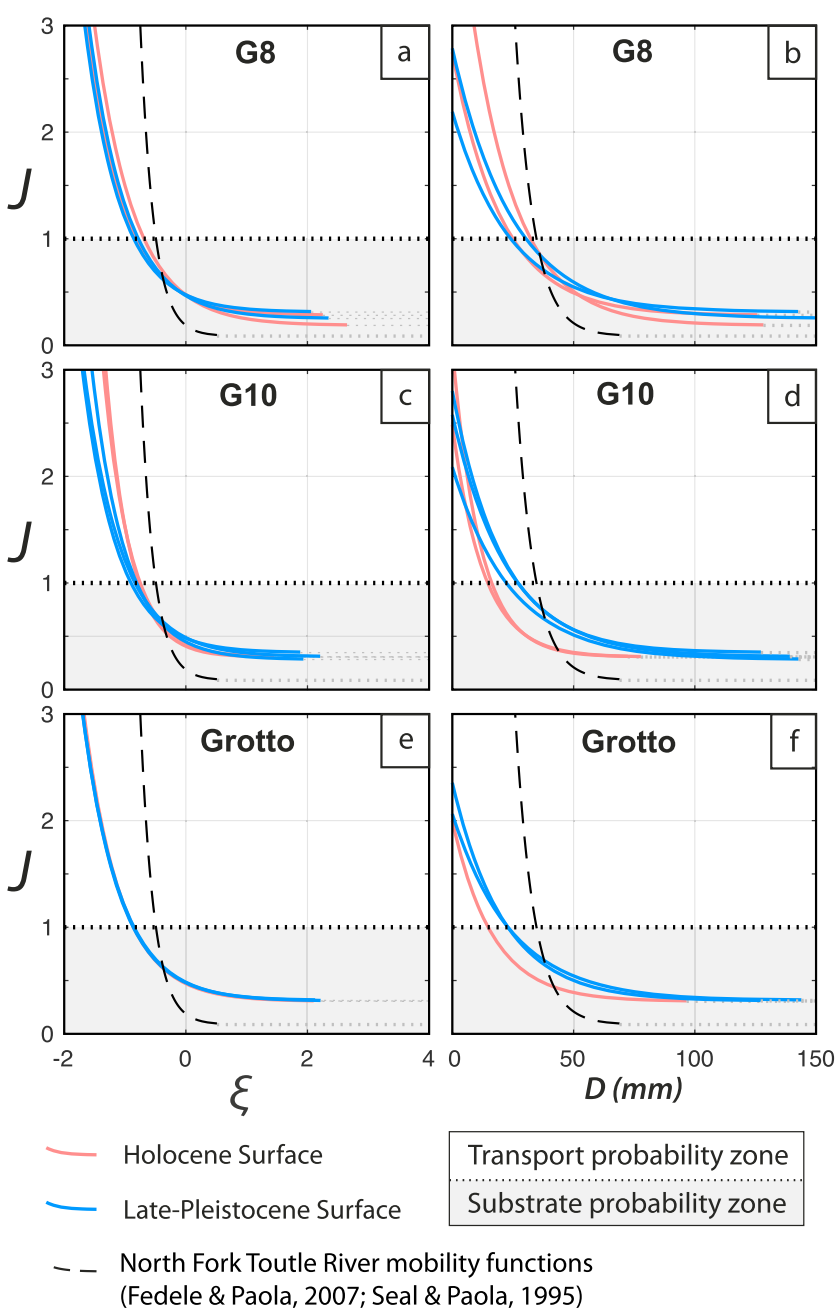

Figure 9. Fan-specific relative mobility curves produced from modeled best fit $J$ parameters $(a, c$, and e) showing the likelihood of given self-similar grain size $(\xi)$ being transported or locked in substrate following the definition of $J$ by Fedele and Paola (2007), where $J<1$ values are more likely to be stored in substrate and $J>1$ values more likely to be transported. Plots $b, d$, and $f$ are the modeled relative mobility regimes calculated for surface-specific mean and standard deviation of grain size, allowing predictions of true grain size $D(\mathrm{~mm})$. Blue lines are the modeled mobility regimes for Pleistocene surfaces, red lines Holocene surfaces.

which tectonic boundary conditions are likely to have been stable. Specifically, $J>1$ values are progressively more mobile (and statistically more likely to be in transport than in the substrate) while $J<1$ values are progressively less mobile. We describe and compare $J=1$ values as a convenient measure that describes the largest time-averaged grain size that is equally likely to be transported versus locked in temporary or long-term storage in the substrate.

Each of the curves (Figures 9a, 9c, and 9e) show a significant fall in grain size mobility before $\xi=0$ for both alluvial fan surfaces (solid lines) and the North Fork Toutle River (Fedele \& Paola, 2007, black dashed line). The main difference between the river versus alluvial fan curves is the intersection between the $J(\xi)$ curve and $J=1$ boundary. The alluvial fan curves have $J=1$ values at approximately -1 to -0.8 values of $\xi$, with the North Fork Toutle curve crossing at a larger value of $-0.3 \xi$ with a moderately steeper decline in mobility compared to the alluvial fan curves.

To relate values of $\xi$ to observed sediment transport systems, we reconstruct a dimensional value of grain size from $\xi$ using the average surface-specific grain size and standard deviation (equation (5) or an approximation from the original study in the case of the North Fork Toutle River (cf. Seal \& Paola, 1995). In doing so we produce corollary functions of grain size mobility showing $\mathrm{J}$ against millimeter grain size for each fan surface (Figures 9b, 9d, and 9f). These plots show that for alluvial fans, Holocene fan surfaces A and B (red curves) 

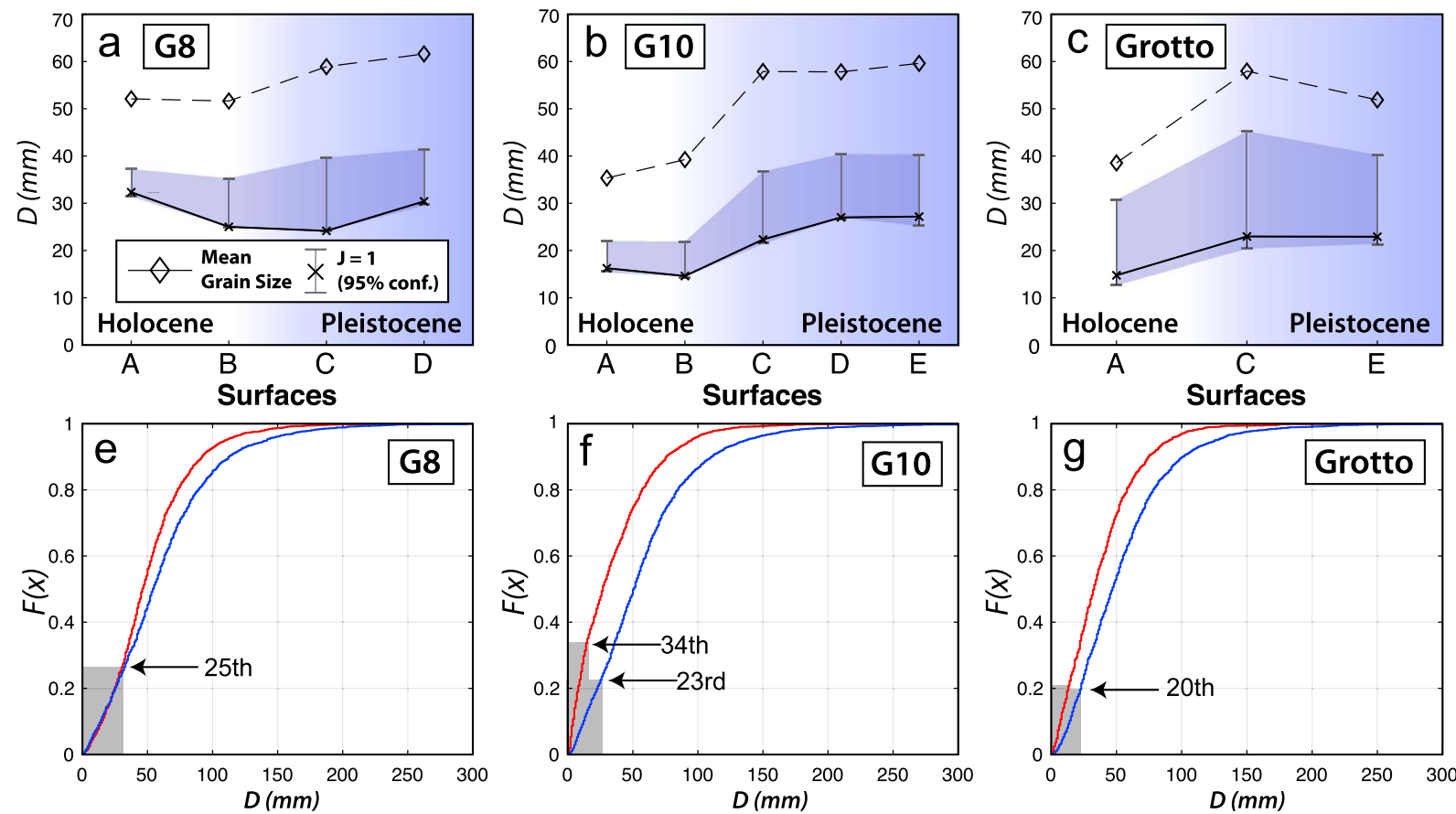

Figure 10. (a-c) Model-predicted equally mobility grain sizes per fan surface, where $J=1$ (Fedele \& Paola, 2007) marked by solid black lines with $95 \%$ confidence. Dashed black lines are the comparative mean grain sizes per surface, with blue hue backgrounds for Pleistocene surfaces. ( $d$ - $f$ ) Field-derived cumulative frequency curves from combined Holocene (red curve) and late-Pleistocene (blue curve) grain size measurements. Gray boxes indicate the envelope of grain size values below the $J=1$ grain size with corresponding percentile of total grains predicted to be in frequent transportation within alluvial fan gravels that are preserved on the fan surface.

have, on average, a steeper decline in $J$ compared to late-Pleistocene surfaces (blue curves), most evident on fans G10 (Figure 9b) and Grotto (Figure 9f). These two curves also suggest that the Holocene fan sediments record lower grain mobility than during the latest Pleistocene, recorded in fan surface $\mathrm{C}$. It is important to note that the $J$ curves remain relatively condensed on G8 for all fan surfaces (Figure 9b), apparently reflecting little change in relative mobility through time.

To explore the importance of different parameterizations of $J$, we also use the North Fork Toutle relative mobility function with mean and standard deviations present on alluvial fans (with an example mean grain size of $51 \mathrm{~mm}$ and standard deviation of $34 \mathrm{~mm}$ ). These curves (black dashed, Figures $9 \mathrm{~b}, 9 \mathrm{~d}$, and $9 \mathrm{f}$ ) exhibit a similar shift to the $J(\xi)$ curves (Figure 9a, 9c, and 9e), with $J=1$ intersections for the alluvial fan curve below $35 \mathrm{~mm}$ using the North Fork Toutle J parameters. In short, the North Fork Toutle $J$ parameterizations predict a higher mobility of smaller, less than $40 \mathrm{~mm}$ grain sizes lower mobility for grain sizes larger than $50 \mathrm{~mm}$ compared to the alluvial fan fits, with a steeper drop from transport and substrate probability states.

To illustrate these differences in relative mobility further, we produce a comparative plot of the $J=1$ grain size for each surface on each fan (Figure 10) with the corresponding variation in mean surface grain size. For each fan the $J=1$ grain size is, within a 95\% confidence envelope, smaller than the mean grain size on each surface by $\sim 15-30 \mathrm{~mm}$ with generally larger values for older fan surfaces $C, D$, and $E$. The exception to this time relationship is fan G8, where the $J=1$ value is marginally greater for Holocene surface $A$ compared to late-Pleistocene surface $C$. For fan $\mathrm{G} 10, J=1$ drops approximately $50 \%$ between fan surfaces $D$ and $A$ (Figure 10b), with a predicted drop of approximately $40 \%$ between C and A for the Grotto fan (Figure 10c).

Using a total grain size cumulative distribution function per fan for both the Holocene and late Pleistocene (Figures 10d-10f), the cumulative percentile of below the $J=1$ value represents the fraction of total material that is modeled to be readily and probabilistically mobile. Irrespective of combined grain size distribution in the Holocene or late Pleistocene, the relative mobility predictions dictate that approximately $30 \%$ of the smallest gravel material preserved on alluvial fans is readily mobile, while the remaining larger $70 \%$ of grain sizes are more likely to be locked within the substrate than in transport. 


\section{Discussion}

\subsection{Grain Size Trends of Death Valley Alluvial Fans}

We provide detailed surface maps for three previously unmapped alluvial fan systems in Death Valley (G8, G10, and the Grotto Canyon fan) using a range of relative age indicators to (i) place surfaces in sequential age order (units $A-E$ ) and (ii) correlate units A-E with dated fan surfaces elsewhere in the basin to divide fan surfaces between the Holocene and late Pleistocene.

From the grain size measurements of 12 alluvial fan surfaces in Death Valley, we have detected a statistically significant change in bulk grain size distributions between younger fan surfaces $A$ and $B$, of Holocene age, and older fan surfaces $C, D$, and E, correlated to the late Pleistocene. These differences constitute a 30-50\% drop in median $\left(D_{50}\right)$ and $\left(D_{84}\right)$ grain size from fan surface $C$ to those of the Holocene, when taken across the combined alluvial fan surfaces (Figure 4). The changes are most pronounced in the coarse $D_{84}$ fraction of material on alluvial fans, evident from both total surface distributions and the comparative spread of individual distributions across each fan. For the oldest $\mathrm{E}$ surfaces, which show the most subdued morphology, it is important to consider whether finer grain size distributions and the increased clast angularity we observe may be product of desert pavement formation, where fracturing is known to occur on the exposed surfaces that can reduce the mean grain size by $10 \mathrm{~mm}$ (Al-Farraj \& Harvey, 2000; see section 5.2). Irrespective of the inclusion of the $E$ surfaces, the clearest shift in bulk grain size distribution occurs over the transition between $A-B$ units and the late-Pleistocene $C$ surfaces, which we interpret to represent a shift in hydraulic and sediment transport conditions within the last $30 \mathrm{ka}$.

From the statistical analysis of grain size distributions we observe an approximately similar ratio of mean grain size and standard deviation downstream such that the coefficient of variation $\left(C_{v}\right)$ of distributions is stable to the first order (Figure 5). These findings broadly agree with Fedele and Paola (2007) and previous studies (cf. D'Arcy et al., 2016; Duller et al., 2010; Whittaker et al., 2011) except for a relatively limited degree of downstream fining observed on some surfaces. A granulometric study of the Hanaupah Canyon fan by lbbeken et al. (1998) also observe no systematic reduction in grain size for preserved Q2 and Q3 with distance from the fan apex, while Stock et al. (2008) observe no fining within the upper $60-80 \%$ of fan lengths, suggesting that limited grain size fining may be a common attribute of some alluvial fans. It is possible to rule out the loss of a fining signal to the reworking of material on fan surfaces over time as we observe the least grain size fining on the youngest Holocene surfaces (Figure 5).

\subsection{Postdepositional Modification of Grain Size}

For the study of grain size distributions on alluvial fan surfaces the formation of desert pavement and other postdepositional modifications of gravel grain size is a potentially important consideration when conducting field measurements in arid locations. For the fan surfaces in this study our field observations suggest that marked desert pavement is limited to the oldest E surfaces, concomitant with a gradual loss of fluvial texture on surface deposits and an increase in clast angularity (see section 3.1). Aside from the observed absence of pavement with relative preservation of bar and swale morphology on surfaces $A-D$, the presence of statistically robust self-similarity of grain sizes on our fan surfaces is an important result that potentially casts doubt on whether postdepositional modification has taken place. However, our reconstructions of relative mobility require an assumption that the gravel particle grain size distribution is the same (or similar) to that at deposition. For our fan surfaces, we base this assumption on the changes in surface morphology relative to the fresh fan deposits, namely, the loss of bar and swale morphology, preservation of clast imbrication, and the development of desert pavement. We also employ a high-measurement count sampling strategy to mitigate spatial heterogeneity of grain size distributions on a given surface either due to inherent fractionation during transport or postdepositional lateral migration of clasts (see section 3.2). We must consider, however, the degree to which postdepositional processes, such as desert pavement formation, have the potential to alter the surface and subsurface grain size through a number of processes such as the modification of grain size distributions in the immediate subsurface by aeolian deposition (Goudie, 2013; McFadden et al., 1987; Pelletier et al., 2007; Wells et al., 1995) and/or the surface fragmentation of clasts (Al-Farraj \& Harvey, 2000). In this discussion we shall consider (i) the likely effect on grain size distributions postdepositional processes would likely produce and (ii) whether any evidence of these effects are present in our field study sites. 
The development of desert pavement is believed to be strongly dependent on the dust influx, producing a layer of fine material below an interlocking armor of coarse material at the surface (McFadden et al., 1987; Pelletier et al., 2007; Wells et al., 1995). Pelletier et al. (2007) show, using a field-calibrated modeling approach from the Fortymile Wash in Amargosa Valley, that the rate of desert pavement development is a nonlinear function of the aeolian deposition rate, with 50\% pavement development potentially taking between 5 and $14 \mathrm{ka}$ to develop for aeolian deposition rates below $0.2 \mathrm{~cm} / \mathrm{kyr}$. For gravel-dominated parent material, such as relict bar and swale surface morphology, vertical clast migration, if it does readily occur, requires a sufficiently thick epipedon layer (Pelletier et al., 2007; Wells et al., 1995) that was not observed on any fan surface in this study (see section 4.1). Furthermore, the lack of observed surface modification on surfaces $A$ and $B$ is corroborated by the agreement between side cut and top surface measurements (see Text S3). For Fan surface $C_{\text {, }}$ preserved bar and swale morphology, degree of desert varnishing, fan terrace height, and proximity to surface $B$ indicate that deposits are between 7 and 24 ka with a limited degree of desert varnish. We therefore interpret that these surfaces do not show desert pavement formation.

It has been demonstrated that changes in spatial heterogeneity of grain size distributions on desert pavements can be inferred from ${ }^{10} \mathrm{Be}$ concentrations in surface sediment, where bar sediment yields an equal or lower ${ }^{10} \mathrm{Be}$ concentration than swale sediment. This contrast enables an estimation of the rate of diffusive smoothing of relict depositional morphology, a process that can take between 170 and $220 \mathrm{ka}$ (Matmon et al., 2006 , 2009). Furthermore, an eventual stabilization of the lateral migration of coarser material from bars into swales can preserve subtle evidence of the original depositional morphology, suggesting that surface clasts remain in situ once this diffused configuration is established and clasts attain a typical interlocking pattern (Matmon et al., 2009). These finding are corroborated by comparative ${ }^{3} \mathrm{H}$ dating of surface clasts and their bedrock source in the Mojave desert, which shows that surface clasts have remained stable atop desert pavements since deposition, with subsurface vertical aggradation of gravel-free layers produced by windblown dust accumulation (Wells et al., 1995). For our study, this suggests the suitability of surface grain size measurements even after bar and swale morphology has been lost, especially if the motivation is to capture a spatially averaged grain size across a wide area.

Surface fragmentation is a further modifier of surface grain size composition; specifically, Al-Farraj and Harvey (2000) show that for 100-ka desert pavements in Oman the mean grain size diameter is $10 \mathrm{~mm}$ smaller on the surface compared with the sub surface, with an increase in angularity for surface clasts. These findings suggest that desert paved surfaces $100 \mathrm{kyr}$ in age or older may exhibit a finer grain size compared to deposition. The angularity of clasts on the oldest $E$ surfaces indicates that some fractionation may have systematically altered the bulk grain size distributions, potentially reducing the size of the largest clasts and lowering the coarse fraction $D_{84}$ grain size.

In general, the potential for postdepositional modification of surface grain size distributions for surfaces A to $D$ is otherwise limited by sampling of grain size across a complete surface and not targeting exclusively bars or swales that inevitably degrade over time. We observe little evidence of substantial desert pavement formation for the majority of surfaces, either from surface morphology or presence of wind-blown deposits in the immediate subsurface. The main exception are the oldest E surfaces with interlocking, angular grains with the greatest loss of original fluvial morphology and thin subsurface layer of fines. While we do not attest that desert pavement is entirely absent from our study sites, the combination of typical sloping fan surfaces and coarse gravel parent material appears to have limited its development, especially in the proximal region of alluvial fans. In terms of the potential to influence grain size results, regardless of self-similar conformance, the observed reduction in $D_{50}$ and $D_{84}$ on both $E$ surfaces compared adjacent $C$ and $D$ surfaces (Figures $4 \mathrm{e}$ and $4 \mathrm{f}$ ) could be the result of surface-wide fragmentation of clasts as desert pavement has developed. This would suggest that the original grain size distribution for $E$ surfaces was more similar in $D_{50}$ and $D_{84}$ grain size to the younger and better preserved $C$ and $D$ surfaces. A further effect of desert pavement formation would be the canceling or subduing of grain size fining trends either by spatially uniform clast migration or the preferential fragmentation of larger clasts. Neither of these processes appears to occur on our study fans as the fining trends are in fact present on some of the older C, D, and E fan surfaces (Figures $5 a-5 c$ ). We reiterate that we would not expect to observe self-similarity between fan surfaces of different age if significant postdepositional reworking of gravel material had occurred, thus altering the observed proportionality of mean and standard deviation (see section 4.3). 


\subsection{Grain Size Self-Similarity}

Following the observation of stable $C_{v}$ downstream, we adopt a self-similar definition of grain size (D'Arcy et al., 2016; Duller et al., 2010; Fedele \& Paola, 2007; Whittaker et al., 2011) and standardized tests of statistical equivalency to show that grain size distributions from hydraulically sorted sediments on alluvial fans in Death Valley are self-similar. From this, we model surface-specific relative grain size mobility using the self-similar solutions of Fedele and Paola (2007) and the relative mobility parameter $J$, which encapsulates long-term hydraulic behaviors to estimate the likelihood of a given grain size being transported or stored in deposits.

In this study, the ratio between the mean grain size and standard deviation $\left(C_{v}\right)$ is approximately stable and non time dependent. Specifically, this study finds $C_{v}$ is between 0.6 and 0.9 that are in broad agreement with previous work by D'Arcy et al. (2016) and Duller et al. (2010), setting empirical boundaries on the likely spread of grain size data in relation to the mean grain size and the shape of grain size distributions.

Miller et al. (2014) conducted a similar study of the Dog Canyon fan in New Mexico, United States, using a combination of manual pebble counts, photogrammetry, and hydraulic measurements. These authors identify a downstream fining trend but their observations show a much larger spread in $C_{v}$ downstream with values of $0.6 \pm 0.3$. Miller et al. (2014) argue that nonstatic $C_{v}$ contradicts the findings of Fedele and Paola (2007) and instead suggest that an alluvial fan may represent a state of constant disequilibrium, where sediment never fully sorts through hydraulic processes to achieve stable $C_{v}$ values downstream. By comparison, our study shows a clear contrast in grain size distributions through time and more stable $C_{v}$ values for each surface. It is possible that the lack of stability in grain size mean and variance obtained by Miller et al. (2014) may be due to a lower grain size sampling resolution by comparison or a true reflection of how not all fans have sufficient hydraulic sorting to produce self-similar grain size distributions, highlighting further heterogeneity between alluvial fans. We note that from the intensive fieldwork in this study, the inherent fractionation of grain sizes on fan surfaces, for example, bar and swale morphology on the surface, obligates a weighted grain size distribution between two grain size fractions to accurately capture the spatially averaged distribution at a given location. From both a strong visual agreement of cumulative frequency curves for self-similar grain size (Figure 6 and Text S4) and K-S tests (Text S3), we argue that there is convincing agreement between self-similar grain size distributions of alluvial fan surfaces (see Text S4).

Our study has identified an intriguing affinity of grain size distributions through time (Figure 6). In focusing on a temporal relationship between grain size distributions and their relative mobility functions, we are not assessing the extraction of sediment along a fixed sediment routing system, but the possibility to assess the relative mobility of material within a fixed spatial reference frame, in this case the alluvial fan. The observation of self-similarity through time poses questions as to how the sediment source and upstream catchment system has evolved through time to retain the same proportionality between the mean and standard deviation. One hypothesis is that the same initial grain size distribution is generated within the catchment and the deposited distribution on the fan surface is a product of changing sediment flux through time, shifting the proportion of coarser material that can propagate to the downstream alluvial fan (e.g., Armitage et al., $2011,2013)$. The fan surfaces we measure were deposited during both the present dry Holocene and wetter late-Pleistocene conditions (see section 2.1); we can therefore also hypothesize that changing water discharges through time may have modified the sediment transport capability on these alluvial fans, changing grain size fining trends preserved in stratigraphy. Furthermore, the presence of self-similarity is also indicative of the dominance of fluvial processes on these alluvial fan surfaces, allowing us to presume they are not a product of stochastically driven debris flow activity and may instead represent a record of average climate.

\subsection{Sediment Mobility on Alluvial Fans}

Observed changes in $J$ functions between fan surfaces of different age, coupled with our observations that postdepositional modification of Holocene and latest Pleistocene surfaces is not significant, implies a change in the grain size relative mobility over time. These changes may be a result of long-term changes in the hydraulics of the upstream channel system or complex dynamics of an alluvial fan distributary system, controlled by changing channel geometries and magnitude frequency of discharge events - changes that will ultimately influence the mechanisms of sediment transport, sorting, and extraction into substrate. When we compare $J=1$ grain sizes between surfaces, we can gauge what grain size is predicted to be equally likely to be in transport versus substrate. These $J=1$ grain sizes are shown to represent the 20 th-35th percentile grain size present in the substrate, where the 1st percentile is the smallest and 100th the largest (cf. Figure 10). 
The potential significance of the $J=1$ grain size is whether it realistically represents material that is equally present in both transport and substrate fractions and how it may compare to the mean or median grain size of the initial grain size distribution.

In general, we hypothesize that the form of the $J$ function will change as a result of a given geomorphological setting and variations in sediment transport regime through time (e.g., late-Pleistocene wetter conditions compared to more arid Holocene conditions), both of which determine the frequency distributions of substrate grain size. While we do not have a precise age control on individual surfaces, there are obvious temporal changes in grain size mobility that show consistency across many of the fan depositional surfaces studied here. For instance, fans G10 and Grotto Canyon show model-predicted $J=1$ grain sizes that are 30-40\% greater for surface $C$ than for surface $A$. These greater values of $J=1$ grain size may reflect a greater competency, averaged over the time span of the depositional unit of a given sediment transport regime to move larger grain sizes.

By comparison, little disparity between $A$ and $D$ surface $J=1$ grain sizes for fan $G 8$ reflects a lack of observable grain size shifts between the surfaces of different age from cumulative frequency curves or comparison of total surface grain size distributions. Field evidence of the reworking and intermingling of sediment, particularly as the incising Holocene channel cannibalizes older Pleistocene surfaces, could explain why the Holocene units on fan G8 show a greater value for $J=1$ grain sizes, closer to the late-Pleistocene values of equal mobility observed on the corresponding G10 and Grotto Canyon fans.

The similar changes in grain size mobility between fans on separate faults that have otherwise low (i.e., $<2$ $\mathrm{mm}$ /year) slip rates, suggests that the changes in $J=1$ grain size values for late Pleistocene and Holocene units are controlled by climatic change and a subsequent sediment transport response, not tectonics. Over this time period, precipitation and temperature are known to have varied considerably in the region; the record of regional pluvial lakes including Lake Manly in Death Valley (Forester et al., 2005; Ibarra et al., 2014; Ku et al., 1998; Lowenstein et al., 1999) showing a major warming and drying over the late-Pleistocene and Holocene transition, the timing of which approximately corresponds with a shift from larger to smaller $J=1$ grain sizes assuming that our $C$ surface does indeed mark this transition. We suggest that the observed shift in relative mobility, deduced from our alluvial fan grain size distributions, represents the preserved stratigraphic signature of a change in precipitation over the last glacial-interglacial transition.

D'Arcy et al. (2016) attributed changes in sediment flux from 70 ka to the present to a $30 \%$ drop in mean annual precipitation during this period. It is possible to hypothesize that either mean water discharges during the late Pleistocene were greater and more capable of transporting coarser material onto alluvial fans or the predicted increases in sediment flux resulted in a further progradation of larger grain sizes downstream. If one of these scenarios is correct, this study is a further indication of the sensitivity of alluvial fans in Death Valley to glacial-interglacial climate change, even for fans 1-2 km in length compared to the 4-5 km length fans in the D'Arcy et al. (2016) study. This study also supports the continued research of preserved fluvial stratigraphy and the interpretation of grain size signals as a valuable archive of past environmental change.

\subsection{Wider Implications and Limitations}

The advantage of self-similar properties is the ability to collapse or cross compare data from sediment routing systems of any scale provided the definition of self-similarity is met. Doing so will enable further progress in identifying simple yet powerful empirical models of landscape and stratigraphic evolution beyond what has already been achieved, that is, tectonic controls on grain size fining (Duller et al., 2010) and the original work by Fedele and Paola (2007).

The self-similar grain size solutions and relative mobility model offers low parameter dependence, facilitating use in scenarios such as the study of ancient fluvially transported deposits where hydraulic constraints are irrecoverably lost (e.g., Whittaker et al., 2011). In principle, it is now possible to estimate the relative mobility regime from the statistical measures of grain size alone, providing a suitable study area and valuable independent assessment of sediment transport regime. Importantly, the model carries with it the implicit assumption that there is a constant dimensionless shear stress downstream, which is reasonable for the study of alluvial fan grain size for timescales longer than $10^{3}$ year due to time averaging of hydraulic processes. Furthermore the constants of $C_{1}$ and $C_{2}$ within their likely range of values (cf. Duller et al., 2010) carry their own assumptions that should be defined appropriately for any system. Deriving grain size relative mobility is 
particularly suited to sedimentary deposits with an abundance of hydraulically sorted gravels, such as alluvial fans or fluvial gravel bars that can be spatially referenced and measured at a high frequency manually or with photogrammetric methods.

To address the motivating question of how sensitive catchment-fan systems are to hydraulic changes through time, we require more field case studies and improved understanding of the behavior of sediment transport on alluvial fans. Our ability to reconstruct climate will inevitably be set by factors such as the sediment accumulation rate and geomorphic processes intrinsic to alluvial fans, posing important questions as to whether discrete high-frequency events can be preserved. To assess any explicit climatic sensitivity, more absolute age constraints are needed for alluvial fan systems in locations with known past climate perturbations. Surface ages enable us to directly compare sediment transport and sediment flux metrics derived from alluvial fan deposits with the range of climate proxies available in the region for the late Pleistocene-Holocene transition. Finally, we note that the derivation of $J$ using the least squares regression analysis of self-similar grain size has been conducted on three alluvial fans in this study. In order to fully test the idea that $J$ may allude to system-specific sediment transport regimes, more grain size distributions from a multitude of environments should be tested, including other fan systems of larger size and/or in differing climatic regimes and histories.

\section{Conclusions}

In principle, simple catchment-fan systems in dry climates offer a means to explore landscape sensitivity to environmental boundary conditions, as they are known to be sensitive to climatic change with near-complete preservation of sediment in alluvial fans downstream. Textural information in grain size distributions, when well preserved, represents a readily measurable product of long-term sediment transport.

Bulk grain size distributions of age-correlated fan surfaces show a drop of $30-50 \%$ in $D_{50}$ and $D_{84}$ grain size over fan surfaces, thought to cover the late Pleistocene to Holocene transition, which are observable on three, 1- to 2-km length alluvial fans in northern Death Valley irrespective of fault, aspect, and lithology. We also demonstrate that the coefficient of variation $\left(C_{v}\right)$ on alluvial fan surfaces are stable to the first order, with values between 0.55 and 0.8 .

We show that formerly disparate and varied grain size distributions collapse onto a single cumulative frequency function when transformed into a self-similar form. K-S tests show an $89 \%$ pass rate when cross-comparing self-similar fan surface distributions, compared to only a $6 \%$ pass rate for unmodified grain size distributions. These tests, coupled with the clear visual overlap of the grain size distributions, strongly suggest that grain size distributions on alluvial fans are self-similar through time.

We apply the self-similar solutions of Fedele and Paola (2007) to derive surface-specific values of the relative mobility parameter $J$ through time, assuming no postdepositional modification of surface grain size. This is a probabilistic nondimensional value that describes the likelihood of a given grain size being transported or locked in substrate and essentially captures long-term hydraulic controls on sediment mobility.

Application of the self-similar solutions produces continuous functions of relative mobility, J, against grain size that we demonstrate which varies relative to the age of the fan surface, with late-Pleistocene-correlated surfaces, showing a greater degree of grain size mobility compared to Holocene surfaces. These changes are evident when we compare the $J=1$ grain sizes for each surface, revealing up to a $40 \%$ drop in $J=1$ grain size between surfaces correlated to the late Pleistocene and those of Holocene age. We argue that these changes constitute a record of stratigraphic grain size change in response to a reduction in rainfall over the glacial-interglacial transition, further supporting the continued study of alluvial fan sediments as valuable archives of environmental change.

In summary, this paper shows the utility of high-resolution grain size collection and analysis. The methods outlined in this paper rely solely on georeferenced grain size data in hydraulically sorted gravel systems, which are capable of exhibiting statistically significant spatial and temporal variation. We suggest we can attribute these changes to a wider climatic control on sedimentation using the self-similar framework that provides a means to quantify the relative mobility of grain sizes over $10^{4}$ timescales. In this regard, the detailed study of grain size is a valuable part of the study of sediment routing system dynamics on the Earth's surface. 


\section{Acknowledgments}

The data set and scripts used to produce the results and figures in this study can be accessed at https://doi.org/10.5281/zenodo.1251929. This research was supported as part of the NERC funded Science and Solution for a Changing Planet Doctoral Training Partnership with the Grantham Institute for Climate Change and the Environment at Imperial College London. We would like to thank Chris Paola for constructive conversations on the subject of grain size mobility and mass extraction downstream that greatly helped refine our conclusions. We also thank Fritz Schlunegger and two anonymous reviewers for their highly constructive suggestions that helped improve the clarity and strength of the manuscript.

\section{References}

Al-Farraj, A., \& Harvey, A. M. (2000). Desert pavement characteristics on wadi terrace and alluvial fan surfaces: Wadi Al-Bih, U.A.E. and Oman Geomorphology, 35(3), 279-297. https://doi.org/10.1016/S0169-555X(00)00049-0

Allen, P. A. (2008). Time scales of tectonic landscapes and their sediment routing systems. Geological Society, London, Special Publications, 296(1), 7-28. https://doi.org/10.1144/SP296.2

Allen, P. A., Armitage, J. J., Carter, A., Duller, R. A., Michael, N. A., Sinclair, H. D., et al. (2013). The Qs problem: Sediment volumetric balance of proximal foreland basin systems. Sedimentology, 60(1), 102-130. https://doi.org/10.1111/sed.12015

Allen, P., \& Densmore, A. (2000). Sediment flux from an uplifting fault block. Basin Research, 12, 367-380. https://doi.org/10.1046/j.1365-2117.2000.00135.x

Allen, P. A., \& Hovius, N. (1998). Sediment supply from landslide-dominated catchments: Implications for basin-margin fans. Basin Research, 10(1), 19-35. https://doi.org/10.1046/j.1365-2117.1998.00060.x

Allen, P. A., Michael, N. A., D’Arcy, M., Roda-Boluda, D. C., Whittaker, A. C., Duller, R. A., \& Armitage, J. J. (2017). Fractionation of grain size in terrestrial sediment routing systems. Basin Research, 29(2), 180-202.

Armitage, J. J., Duller, R. A., Whittaker, A. C., \& Allen, P. A. (2011). Transformation of tectonic and climatic signals from source to sedimentary archive. Nature Geoscience, 4(4), $231-235$

Armitage, J. J., Jones, T. D., Duller, R. A., Whittaker, A. C., \& Allen, P. A. (2013). Temporal buffering of climate-driven sediment flux cycles by transient catchment response. Earth and Planetary Science Letters, 369, 200-210. https://doi.org/10.1016/j.epsl.2013.03.020

Bacon, S. N., Burke, R. M., Pezzopane, S. K., \& Jayko, A. S. (2006). Last Glacial Maximum and Holocene lake levels of Owens Lake, eastern California. Quaternary Science Reviews, 25(11-12), 1264-1282. https://doi.org/10.1016/j.quascirev.2005.10.014

Blackwelder, E. (1933). Lake Manly: An extinct lake of Death Valley. Geographical Review, 23(3), 464-471.

Blair, T. (1999a). Sedimentary processes and facies of the waterlaid Anvil Spring Canyon alluvial fan, Death Valley, California. Sedimentology, 46, 913-940. https://doi.org/10.1046/j.1365-3091.1999.00259.x

Blair, T. (1999b). Sedimentology of the debris-flow-dominate Warm Spring Canyon alluvial fan, Death Valley, California. Sedimentology, 46, 941-965. https://doi.org/10.1046/j.1365-3091.1999.00260.x

Blair, T. (1999c). Cause of dominance by sheetflood vs. debris-flow processes on two adjoining alluvial fans, Death Valley, California. Sedimentology, 46, 1015-1028. https://doi.org/10.1046/j.1365-3091.1999.00261.x

Blair, T. (2000). Sedimentology and progressive tectonic unconformities of the sheetflood-dominated Hell's Gate alluvial fan, Death Valley, California. Sedimentary geology, 132, 233-262. https://doi.org/10.1016/S0037-0738(00)00010-5

Blair, T. C., \& McPherson, J. G. (1994). Alluvial fans and their natural distinction from rivers based on morphology, hydraulic processes, sedimentary processes, and facies assemblages. Journal of Sedimentary Research, 64(3a), 450-489. https://doi.org/10.1306/D4267DDE-2B26-11D7-8648000102C1865D

Blott, S. J., \& Pye, K. (2008). Particle shape: A review and new methods of characterization and classification. Sedimentology, 55(1), 31-63. https://doi.org/10.1111/j.1365-3091.2007.00892.x

Blum, M. D., \& Törnqvist, T. E. (2000). Fluvial responses to climate and sea-level change: A review and look forward. Sedimentology, 47, $2-48$. https://doi.org/10.1046/j.1365-3091.2000.00008.x

Bull, W. (1964). Geomorphology of segmented alluvial fans in western Fresno County California (Tech. Rep.). Washington, DC: U.S. Government Printing Office.

Bull, W. B. (1977). The alluvial-fan environment. Progress in Physical Geography, 1(2), 222-270. https://doi.org/10.1177/ 030913337700100202

Bull, W. (1991). Geomorphic Responses to Climatic Change. New York: Oxford University Press.

Bunte, K., Abt, S., \& C. Rocky Mountain Research Station (Fort Collins) (2001). Sampling surface and subsurface particle-size distributions in wadable gravel and cobble-bed streams for analyses in sediment transport, hydraulics, and streambed monitoring. General technical report RMRS, U.S. Dept of Agriculture, Forest Service, Rocky Mountain Research Station.

Burchfiel, B. C., \& Stewart, J. H. (1966). "Pull-apart” origin of the central segment of Death Valley, California. Geological Society of America Bulletin, 77(4), 439-442. https://doi.org/10.1130/0016-7606(1966)77[439:POOTCS]2.0.CO;2

Clarke, L., Quine, T., \& Nicholas, A. (2010). An experimental investigation of autogenic behaviour during alluvial fan evolution. Geomorphology, 115, 278-285. https://doi.org/10.1016/j.geomorph.2009.06.033

Clevis, Q., de Boer, P., \& Wachter, M. (2003). Numerical modelling of drainage basin evolution and three-dimensional alluvial fan stratigraphy. Sedimentary Geology, 163(1-2), 85-110. https://doi.org/https://doi.org/10.1016/S0037-0738(03)00174-X

Coleman, T. F., \& Li, Y. (1993). An interior trust region approach for nonlinear minimization subject to bounds (Tech. Rep.). Ithaca, New York: Cornell University.

Cowie, P., Whittaker, A., Attal, M., Roberts, G., Tucker, G., \& Ganas, A. (2008). New constraints on sediment-flux-dependent river incision: Implications for extracting tectonic signals from river profiles. Geology, 36, 535-538. https://doi.org/10.1130/G24681A.1

D'Arcy, M., Whittaker, A. C., \& Roda-Boluda, D. C. (2016). Measuring alluvial fan sensitivity to past climate changes using a self-similarity approach to grain-size fining, Death Valley, California. Sedimentology, 64(2), 388-424.

Denny, C. S. (1965). Alluvial fans in the Death Valley region, California and Nevada (Tech. Rep.). Washington, DC: U.S. Government Printing Office.

Denny, C. S. (1967). Fans and pediments. American Journal of Science, 265(2), 81 - 105. https://doi.org/10.2475/ajs.265.2.81

Densmore, A. L., Allen, P. A., \& Simpson, G. (2007). Development and response of a coupled catchment fan system under changing tectonic and climatic forcing. Journal of Geophysical Research, 112, F01002. https://doi.org/10.1029/2006JF000474

DiBiase, R. A., \& Whipple, K. X. (2011). The influence of erosion thresholds and runoff variability on the relationships among topography, climate, and erosion rate. Journal of Geophysical Research, 116, F04036. https://doi.org/10.1029/2011JF002095

Dühnforth, M., Densmore, A. L., Ivy-Ochs, S., Allen, P., \& Kubik, P. W. (2017). Early to late Pleistocene history of debris-flow fan evolution in western Death Valley (California) using cosmogenic ${ }^{10} \mathrm{Be}$ and ${ }^{26} \mathrm{Al}$. Geomorphology, 281, 53-65. https://doi.org/10.1016/j.geomorph.2016.12.020

Duller, R. A., Whittaker, A. C., Fedele, J. J., Whitchurch, A. L., Springett, J., Smithells, R., et al. (2010). From grain size to tectonics. Journal of Geophysical Research, 115, F03022. https://doi.org/10.1029/2009JF001495

Fedele, J. J., \& Paola, C. (2007). Similarity solutions for fluvial sediment fining by selective deposition. Journal of Geophysical Research, 112, F02038. https://doi.org/10.1029/2005JF000409

Ferrill, D., Morris, A., Stamatakos, J., Waiting, D., Donelick, R., \& Blythe, A. (2012). Constraints on exhumation and extensional faulting in southwestern Nevada and eastern California, USA, from zircon and apatite thermochronology. Lithosphere, 4, 63-76. https://doi.org/10.1130/L171.1 
Foreman, B. Z. (2014). Climate-driven generation of a fluvial sheet sand body at the Paleocene-Eocene boundary in north-west Wyoming (USA). Basin Research, 26, 225-241. https://doi.org/10.1111/bre.12027

Forester, R. M., Lowenstein, T. K., \& Spencer, R. J. (2005). An ostracode based paleolimnologic and paleohydrologic history of Death Valley: 200 to 0 ka. Geological Society of America Bulletin, 117(11-12), 1379-1386. https://doi.org/10.1130/B25637.1

Forzoni, A., Storms, J., \& Whittaker, A. (2014). Delayed delivery from the sediment factory: Modeling the impact of catchment response time to tectonics on sediment flux and fluvio-deltaic stratigraphy. Earth Surface Processes and Landforms, 39(5), 689-704. https://doi.org/10.1002/esp.3538

Frankel, K. L., Brantley, K. S., Dolan, J. F., Finkel, R. C., Klinger, R. E., Knott, J. R., et al. (2007). Cosmogenic ${ }^{10} \mathrm{Be} \mathrm{and}^{36} \mathrm{Cl}$ geochronology of offs et alluvial fans along the northern Death Valley fault zone: Implications for transient strain in the eastern California shear zone. Journal of Geophysical Research, 112, B06407. https://doi.org/10.1029/2006JB004350

Frankel, K. L., \& Dolan, J. F. (2007). Characterizing arid region alluvial fan surface roughness with airborne laser swath mapping digital topographic data. Journal of Geophysical Research, 112, F02025. https://doi.org/10.1029/2006JF000644

Ganti, V., Chu, Z., Lamb, M., Nittrouer, J., \& Parker, G. (2014). Testing morphodynamic controls on the location and frequency of river avulsions on fans versus deltas: Huanghe (Yellow River), China. Geophysical Research Letters, 41, 7882-7890. https://doi.org/10.1002/2014GL061918

Garefalakis, P., \& Schlunegger, F. (2018). Link between concentrations of sediment flux and deep crustal processes beneath the European Alps. Scientific Reports, 8, 183. https://doi.org/10.1038/s41598-017-17182-8

Gillespie, A., Kahle, A., \& Palluconi, F. (1984). Mapping alluvial fans in Death Valley, California, using multichannel thermal infrared images. Geophysical Research Letters, 11(11), 1153-1156. https://doi.org/10.1029/GL011i011p01153

Goudie, A. S. (2013). Rock weathering and desert surfaces. Cambridge, UK: Cambridge University Press. https://doi.org/10.1017/ CBO9780511794261.003

Harvey, A. (2002). The role of base-level change in the dissection of alluvial fans: Case studies from southeast Spain and Nevada. Geomorphology, 45(1), 67-87. https://doi.org/https://doi.org/10.1016/S0169-555X(01)00190-8

Harvey, A. M. (2005). Differential effects of base-level, tectonic setting and climatic change on Quaternary alluvial fans in the northern Great Basin, Nevada, USA. Geological Society London Special Publications, 251(1), 117-131. https://doi.org/10.1144/GSL.SP.2005.251.01.09

Harvey, A. (2012). The coupling status of alluvial fans and debris cones: A review and synthesis. Earth Surface Processes and Landforms, 37, 64-76. https://doi.org/10.1002/esp.2213

Hijmans, R., Cameron, S., Parra, J., Jones, P., \& Jarvis, A. (2005). Very high resolution interpolated climate surfaces for global land areas. International Journal of Climatology, 25, 1965-1978. https://doi.org/10.1002/joc.1276

Hooke, R. L. (1968). Steady-state relationships on arid-region alluvial fans in closed basins. American Journal of Science, 266(8), 609-629.

Hooke, R. (1972). Geomorphic evidence for Late-Wisconsin and Holocene tectonic deformation, Death Valley, California. Geological Society of America Bulletin, 83, 2073-2098. https://doi.org/10.1130/0016-7606(1972)83[2073:GEFLAH]2.0.CO;2

Hooke, R., \& Dorn, R. (1992). Segmentation of alluvial fans in Death Valley, California: New insights from surface exposure dating and laboratory modelling. Earth Surface Processes and Landforms, 17(6), 557-574. https://doi.org/10.1002/esp.3290170603

Hunt, C. B., \& Mabey, D. R. (1966). Stratigraphy and structure, Death Valley (Tech. Rep.). California: USGS.

Ibarra, D. E., Egger, A. E., Weaver, K. L., Harris, C. R., \& Maher, K. (2014). Rise and fall of late Pleistocene pluvial lakes in response to reduced evaporation and precipitation: Evidence from Lake Surprise, California. GSA Bulletin, 126(11-12), 1387-1415. https://doi.org/10.1130/B31014.1

Ibbeken, H., Warnke, D. A., \& Diepenbroek, M. (1998). Granulometric study of the Hanaupah Fan, Death Valley, California. Earth Surface Processes and Landforms, 23(6), 481-492. https://doi.org/10.1002/(SICI) 1096-9837(199806)23:6<481::AID-ESP906>3.0.CO;2-T Inman, D. L. (1952). Measures for describing the size distribution of sediments. Journal of Sedimentary Research, 22(3), $125-145$. Jerolmack, D. J., \& Paola, C. (2010). Shredding of environmental signals by sediment transport. Geophysical Research Letters, 37, L19401. https://doi.org/10.1029/2010GL044638

Jerolmack, D. J., \& Sadler, P. (2007). Transience and persistence in the depositional record of continental margins. Journal of Geophysical Research, 112, F03S13. https://doi.org/10.1029/2006JF000555

Kemp, D. B. (2012). Stochastic and deterministic controls on stratigraphic completeness and fidelity. International Journal of Earth Sciences, 101(8), 2225-2238. https://doi.org/10.1007/s00531-012-0784-1

Kim, W., \& Jerolmack, D. (2008). The pulse of calm fan deltas. Journal of Geology, 116, 315-330. https://doi.org/10.1086/588830

Kim, W., \& Paola, C. (2007). Long-period cyclic sedimentation with constant tectonic forcing in an experimental relay ramp. Geology, 35(4), 331-334. https://doi.org/10.1130/G23194A.1

Klinger, R. (2002). Quaternary stratigraphy and geomorphology of northern Death Valley - Implications for tectonic activity along the northern Death Valley fault (PhD thesis). Boulder, CO: University of Colorado.

Knott, J. R., Sarna-Wojcicki, A. M., Machette, M. N., \& Klinger, R. E. (2005). Upper Neogene stratigraphy and tectonics of Death Valley - A review. Earth Science Reviews, 73(1-4), 245-270. https://doi.org/10.1016/j.earscirev.2005.07.004

Kondolf, G. (1997). Application of the pebble count: Notes on purpose, method, and variants. Journal of the American Water Resources Association, 33(1), 79-87. https://doi.org/10.1111/j.1752-1688.1997.tb04084.x

Krumbein, W. C. (1941). Measurement and geological significance of shape and roundness of sedimentary particles. Journal of Sedimentary Research, 11(2), 64-72. https://doi.org/10.1306/D42690F3-2B26-11D7-8648000102C1865D

Ku, T., Luo, S., Lowenstein, T., Li, J., \& Spencer, R. (1998). U-series chronology of lacustrine deposits in Death Valley, California. Quaternary Research, 50, 261-275. https://doi.org/10.1006/qres.1998.1995

Leeder, M. R., Harris, T., \& Kirkby, M. J. (1998). Sediment supply and climate change: Implications for basin stratigraphy. Basin Research, 10(1), 7-18. https://doi.org/10.1046/j.1365-2117.1998.00054.x

Litty, C., \& Schlunegger, F. (2017). Controls on pebbles' size and shape in streams of the Swiss Alps. Journal of Geology, $125(1), 101-112$. https://doi.org/10.1086/689183

Litty, C., Schlunegger, F., \& Viveen, W. (2017). Possible threshold controls on sediment grain properties of Peruvian coastal river basins. Earth Surface Dynamics, 5(3), 571-583. https://doi.org/10.5194/esurf-5-571-2017

Liu, T., \& Broecker, W. S. (2000). How fast does rock varnish grow? Geology, 28(2), 183-186. https://doi.org/10.1130/0091-7613 (2000) $28<183:$ HFDRVG $>2.0$. CO;2

Lowenstein, T., Li, J., Brown, C., Roberts, S., Ku, T., Luo, S., \& Yang, W. (1999). 200 ky paleoclimate record from Death Valley salt core. Geology, 27, 3-6. https://doi.org/10.1130/0091-7613(1999)027<0003:KYPRFD>2.3.CO;2

Machette, M. N., Johnson, M. L., \& Slate, J. L. (2001). Quaternary and Late Pliocene geology of the Death Valley region : Recent observations on tectonics, stratigraphy, and lake cycles (guidebook for the 2001 Pacific Friends of the Pleistocene fieldtrip) (Tech. Rep.). U. S. Geological Survey: U S Dept. of the Interior. 
Machette, M., \& Klinger, R. (2002). Quaternary fault and fold database of the United States. U.S. Geological Survey website.

Machette, M. N., Slate, J. L., \& Phillips, F. M. (2008). Terrestrial cosmogenic-nuclide dating of alluvial fans in Death Valley. California, U.S. Geological Survey Professional Paper, 1755. Denver, CO: Denver Publishing Service Center.

Malmon, D. V., Dunne, T., \& Reneau, S. L. (2003). Stochastic theory of particle trajectories through alluvial valley floors. Journal of Geology, 111(5), 525-542. https://doi.org/10.1086/376764

Marcus, W. A., Ladd, S. C., Stoughton, J. A., \& Stock, J. W. (1995). Pebble counts and the role of user-dependent bias in documenting sediment size distributions. Water Resources Research, 31(10), 2625-2631. https://doi.org/10.1029/95WR02171

Matmon, A., Nichols, K., \& Finkel, R. (2006). Isotopic insights into smoothening of abandoned fan surfaces, Southern California. Quaternary Research, 66(1), 109-118. https://doi.org/https://doi.org/10.1016/j.yqres.2006.02.010

Matmon, A., Simhai, O., Amit, R., Haviv, I., Porat, N., \& McDonald, E. (2009). Desert pavement-coated surfaces in extreme deserts present the longest-lived landforms on Earth. Geological Society of America Bulletin, 121(5-6), 688-697. https://doi.org/10.1130/B26422.1

McFadden, L. D., Wells, S. G., \& Jercinovich, M. J. (1987). Influences of eolian and pedogenic processes on the origin and evolution of desert pavements. Geology, 15(6), 504-508. https://doi.org/10.1130/0091-7613(1987)15<504:IOEAPP>2.0.CO;2

Michael, N. A., Whittaker, A. C., \& Allen, P. A. (2013). The functioning of sediment routing systems using a mass balance approach: Example from the Eocene of the Southern Pyrenees. Journal of Geology, 121, 581-606. https://doi.org/https://doi.org/10.1086/673176

Michael, N. A., Whittaker, A. C., Carter, A., \& Allen, P. A. (2014). Volumetric budget and grain-size fractionation of a geological sediment routing system: Eocene Escanilla Formation, south-central Pyrenees. Geological Society of America Bulletin, 126, 585-599. https://doi.org/10.1130/B30954.1

Miller, M. M., Johnson, D. J., Dixon, T. H., \& Dokka, R. K. (2001). Refined kinematics of the eastern California shear zone from GPS observations, 1993-1998. Journal of Geophysical Research, 106(B2), 2245-2263. https://doi.org/10.1029/2000JB900328

Miller, K., Reitz, M., \& Jerolmack, D. (2014). Generalized sorting profile of alluvial fans. Geophysical Research Letters, 41, $7191-7199$. https://doi.org/10.1002/2014GL060991

Miller, D., Schmidt, K., Mahan, S., McGeehin, J., Owen, L., Barron, J., et al. (2010). Holocene landscape response to seasonality of storms in the Mojave Desert. Quaternary International, 215, 45-61. https://doi.org/10.1016/j.quaint.2009.10.001

Mohrig, D., Heller, P. L., Paola, C., \& Lyons, W. J. (2000). Interpreting avulsion process from ancient alluvial sequences: Guadalope-Matarranya system (Northern Spain) and Wasatch formation (Western Colorado). Geological Society of America Bulletin, 112(12), $1787-1803$. https://doi.org/10.1130/0016-7606(2000)112<1787:IAPFAA>2.0.CO;2

Nicholas, A., Clarke, L., \& Quine, T. (2009). A numerical modelling and experimental study of flow width dynamics on alluvial fans. Earth Surface Processes and Landforms, 34, 1985-1993. https://doi.org/10.1002/esp.1839

Nichols, G. J., \& Fisher, J. A. (2007). Processes, facies and architecture of fluvial distributary system deposits. Sedimentary Geology, 195, 75-90. https://doi.org/10.1016/j.sedgeo.2006.07.004

Norton, I. (2011). Two-stage formation of Death Valley. Geosphere, 7(1), 171-182. https://doi.org/10.1130/GES00588.1

Owen, L. A., Frankel, K. L., Knott, J. R., Reynhout, S., Finkel, R. C., Dolan, J. F., \& Lee, J. (2011). Beryllium-10 terrestrial cosmogenic nuclide surface exposure dating of quaternary landforms in Death Valley. Geomorphology, 125, 541-557. https://doi.org/10.1016/j.geomorph.2010.10.024

Paola, C. (2000). Quantitative models of sedimentary basin filling. Sedimentology, 47, 121-178. https://doi.org/10.1046/j.1365-3091.2000.00006.x

Paola, C., Heller, P. L., \& Angevine, C. L. (1992). The large-scale dynamics of grain-size variation in alluvial basins, 1: Theory. Basin Research, 4(2), 73-90. https://doi.org/10.1111/j.1365-2117.1992.tb00145.x

Paola, C., \& Martin, J. (2012). Mass-balance effects in depositional systems. Journal of Sedimentary Research, 82, $435-450$.

Parker, G. (1990a). The "acronym" series of Pascal programs for computing bedload transport in gravel rivers. Minneapolis, MN: St. Anthony Falls Hydraulic Laboratory, University of Minnesota.

Parker, G. (1990b). Surface-based bedload transport relation for gravel rivers. Journal of Hydraulic Research, 28(4), 417-436. https://doi.org/10.1080/00221689009499058

Parker, G. (1991a). Selective sorting and abrasion of river gravel 1: Theory. Journal of Hydraulic Engineering, 117, $131-149$. https://doi.org/10.1061/(ASCE)0733-9429(1991)117.2.131

Parker, G. (1991b). Selective sorting and abrasion of river gravel 2: Applications. Journal of Hydraulic Engineering, 117, $150-171$. https://doi.org/10.1061/(ASCE)0733-9429(1991)117.2.150

Parker, G., \& Toro-Escobar, C. M. (2002). Equal mobility of gravel in streams: The remains of the day. Water Resources Research, 38(11), 1264. https://doi.org/10.1029/2001WR000669

Pelletier, J. D., Cline, M., \& DeLong, S. B. (2007). Desert pavement dynamics: Numerical modeling and field-based calibration. Earth Surface Processes and Landforms, 32(13), 1913-1927. https://doi.org/10.1002/esp.1500

Piety, L. (1996). Compilation of known or suspected quaternary faults within $100 \mathrm{~km}$ of Yucca Mountain (Tech. Rep.). Denver, CO: U.S. Geological Survey.

Quigley, M., Sandiford, M., \& Cupper, M. (2007). Distinguishing tectonic from climatic controls on range-front sedimentation. Basin Research, 19, 491 - 505. https://doi.org/10.1111/j.1365-2117.2007.00336.x

Reitz, M. D., \& Jerolmack, D. J. (2012). Experimental alluvial fan evolution: Channel dynamics, slope controls, and shoreline growth. Journal of Geophysical Research, 117, F02021. https://doi.org/10.1029/2011JF002261

Riebe, C. S., Sklar, L. S., Lukens, C. E., \& Shuster, D. L. (2015). Climate and topography control the size and flux of sediment produced on steep mountain slopes. Proceedings of the National Academy of Sciences, 112(51), 15,574-15,579. https://doi.org/10.1073/pnas.1503567112

Ritter, J., Miller, J., Enzel, Y., \& Wells, S. (1995). Reconciling the roles of tectonism and climate in Quaternary alluvial-fan evolution. Geology, 23, 245-248. https://doi.org/10.1130/0091-7613(1995)023<0245:RTROTA > 2.3.CO;2

Robinson, R., \& Slingerland, R. (1998). Origin of fluvial grain-size trends in a foreland basin: Pocono Formation on the central Appalachian basin. Journal of Sedimentary Research, 68, 473-486.

Rohais, S., Bonnet, S., \& Eschard, R. (2012). Sedimentary record of tectonic and climatic erosional perturbations in an experimental coupled catchment-fan system. Basin Research, 24, 198-212. https://doi.org/10.1111/j.1365-2117.2011.00520.x

Sadler, P. (1981). Sediment accumulation rates and the completeness of stratigraphic sections. The Journal of Geology, 89(5), 569-584.

Sadler, P. M., \& Strauss, D. J. (1990). Estimation of completeness of stratigraphical sections using empirical data and theoretical models. Journal of the Geological Society, 147(3), 471-485. https://doi.org/10.1144/gsjgs.147.3.0471

Sambrook Smith, G. H., Best, J. L., Ashworth, P. J., Lane, S. N., Parker, N. O., Lunt, I. A., et al. (2010). Can we distinguish flood frequency and magnitude in the sedimentological record of rivers? Geology, 38(7), 579-582. https://doi.org/10.1130/G30861.1 
Savi, S., Norton, K., Picotti, V., Akcar, N., Delunel, R., Brardinoni, F., et al. (2014). Quantifying sediment supply at the end of the last glaciation: Dynamic reconstruction of an alpine debris-flow fan. Geological Society of America Bulletin, 126, $773-790$. https://doi.org/10.1130/B30849.1

Schlunegger, F., \& Norton, K. P. (2013). Headward retreat of streams in the Late Oligocene to Early Miocene Swiss Alps. Sedimentology, 60(1), $85-101$. https://doi.org/10.1111/sed.12010

Schlunegger, F., \& Norton, K. P. (2015). Climate vs. tectonics: The competing roles of Late Oligocene warming and Alpine orogenesis in constructing alluvial megafan sequences in the North Alpine foreland basin. Basin Research, 27, 230-245. https://doi.org/10.1111/bre.12070

Schmitz, B., \& Pujalte, V. (2007). Abrupt increase in seasonal extreme precipitation at the Paleocene-Eocene boundary. Geology, 35(3), 215-218. https://doi.org/10.1130/G23261A.1

Seal, R., \& Paola, C. (1995). Observations of downstream fining on the North Fork Toutle River near Mount St. Helens, Washington. Water Resources Research, 31(5), 1409-1419. https://doi.org/10.1029/94WR02976

Simpson, G., \& Castelltort, S. (2012). Model shows that rivers transmit high-frequency climate cycles to the sedimentary record. Geology, 40(12), 1131-1134. https://doi.org/10.1130/G33451.1

Sklar, L. S., Riebe, C. S., Marshall, J. A., Genetti, J., Leclere, S., Lukens, C. L., \& Merces, V. (2017). The problem of predicting the size distribution of sediment supplied by hillslopes to rivers. Geomorphology, 277, 31-49. https://doi.org/https://doi.org/10.1016/j.geomorph.2016.05.005

Sohn, M., Knott, J., \& Mahan, S. (2014). Paleoseismology of the southern section of the Black Mountains and Southern Death Valley Fault Zones, Death Valley, United States. Environmental \& Engineering Geoscience, 20, 177-197.

Sohn, M., Mahan, S., Knott, J., \& Bowman, D. (2007). Luminescence ages for alluvial-fan deposits in Southern Death Valley: Implications for climate-driven sedimentation along a tectonically active mountain front. Quaternary International, 166, 49-60. https://doi.org/10.1016/j.quaint.2007.01.002

Sternberg, H. (1875). Untersuchungen über Längen und Querprofil geschiebeführnde Flüsse. Zeitschrift fur Bauwesen, 25, $483-506$.

Stock, J. D., Schmidt, K. M., \& Miller, D. M. (2008). Controls on alluvial fan long-profiles. Geological Society of America Bulletin, 120, 619-640. https://doi.org/10.1130/B26208.1

Strom, K. B., Kuhns, R. D., \& Lucas, H. J. (2010). Comparison of automated image-based grain sizing to standard pebble-count methods. Journal of Hydraulic Engineering, 136(8), 461-473. https://doi.org/10.1061/(ASCE)HY.1943-7900.0000198

Strong, N., Sheets, B., Hickson, T., \& Paola, C. (2009). A mass-balance framework for quantifying downstream changes in fluvial architecture (pp. 243-253). Blackwell Publishing Ltd. https://doi.org/10.1002/9781444304350.ch14

Suresh, N., Bagati, T., Kumar, R., \& Thakur, V. (2007). Evolution of Quaternary alluvial fans and terraces in the intramontane Pinjaur Dun, Sub-Himalaya, NW India: Interaction between tectonics and climate change. Sedimentology, 54, 809-833. https://doi.org/10.1111/j.1365-3091.2007.00861.x

Syvitski, J. P. M., \& Milliman, J. D. (2007). Geology, geography, and humans battle for dominance over the delivery of fluvial sediment to the coastal ocean. Journal of Geology, 115, 1-19. https://doi.org/10.1086/509246

Toro-Escobar, C. M., Paola, C., \& Parker, G. (1996). Transfer function for the deposition of poorly sorted gravel in response to streambed aggradation. Journal of Hydraulic Research, 34(1), 35-53. https://doi.org/10.1080/00221689609498763

Wells, S. G., McFadden, L. D., Poths, J., \& Olinger, C. T. (1995). Cosmogenic ${ }^{3}$ He surface-exposure dating of stone pavements: Implications for landscape evolution in deserts. Geology, 23(7), 613-616. https://doi.org/10.1130/0091-7613(1995)023<0613:CHSEDO>2.3.CO;2

Whipple, K., \& Trayler, C. (1996). Tectonic control of fan size: The importance of spatially variable subsidence rates. Basin Research, 8, 351-366. https://doi.org/10.1046/j.1365-2117.1996.00129.x

Whittaker, A., Attal, M., \& Allenn, P. (2010). Characterising the origin, nature and fate of sediment exported from catchments perturbed by active tectonics. Basin Research, 22, 809-828. https://doi.org/10.1111/j.1365-2117.2009.00447.x

Whittaker, A. C., Duller, R. A., Springett, J., Smithells, R., Whitchurch, A. L., \& Allen, P. A. (2011). Decoding downstream trends in stratigraphic grain size as a function of tectonic subsidence and sediment supply. Geological Society of America Bulletin, 123(7-8), 1363-1382. https://doi.org/10.1130/B30351.1

Winograd, I., Coplen, T., Landwehr, J., Riggs, A., Ludwig, K., Szabo, B., et al. (1992). Continuous 500,000-year climate record from vein calcite in Devils Hole, Nevada. Science, 258, 255-260. https://doi.org/10.1126/science.258.5080.255

Wohl, E., Anthony, D., Madsen, S., \& Thompson, D. (1996). A comparison of surface sampling methods for coarse fluvial sediments. Water Resources Research, 32(10), 3219-3226. https://doi.org/10.1029/96WR01527

Wolman, M. (1954). A method of sampling coarse river-bed material. Transactions of the American Geophysical Union, 35(6), $951-956$

Workman, J. B., Menges, C. M., Page, W. R., Taylor, E. M., Ekren, E. B., Rowley, P. D., et al. (2002). Geologic map of the Death Valley ground-water model area, Nevada and California (Tech. Rep.). Reston, VA: USGS.

Yang, W., Lowenstein, T., Krouse, H., Spencer, R., \& Ku, T. (2005). A 200,000-year delta O-18 record of closed-basin lacustrine calcite, Death Valley, California. Chemical Geology, 216, 99-111. https://doi.org/10.1016/j.chemgeo.2004.11.005 